MUÑOZ L., José; FERNÁNDEZ C., José Angel "Estudio dogmático penal de los artículos 291 del Código penal y 136 de la Ley General de Pesca y Acuicultura. A propósito del caso del Santuario de la Naturaleza Carlos Anwandter.

Polit. crim. Vol. 5, No 10 (Diciembre 2010), Art. 4, pp. 410 - 454.

[http://www.politicacriminal.cl/Vol_05/n_10/Vol5N10A4.pdf]

\title{
Estudio dogmático penal de los artículos 291 del Código penal y 136 de la Ley General de Pesca y Acuicultura. A propósito del caso del Santuario de la Naturaleza Carlos Anwandter
}

José Muñoz Lorente

Dr. en Derecho y Prof. Titular de Derecho Penal de la Facultad de Ciencias Sociales y Jurídicas de la Universidad Carlos III de Madrid

jose.munoz@uc3m.es

José Ángel Fernández Cruz

Dr. en Derecho y Prof. de Derecho Penal de la Facultad de Ciencias Jurídicas y Sociales de la Universidad Austral de Chile autoriamediata@gmail.com

\section{Resumen}

El presente estudio analiza los principales problemas dogmáticos de los artículos $291 \mathrm{CP}$ y 136 de la Ley de Pesca y Acuicultura. Hemos tomado como referencia el conocido caso del Santuario de la Naturaleza Carlos Anwandter (Valdivia, Chile), paradigma a la hora de constatar las deficiencias en la protección del medio ambiente en Chile.

\section{Palabras Clave}

Prescripción ilegítima, derecho penal ambiental, criminalidad empresarial

\begin{abstract}
This study analyzes the doctrinal interpretation problems of articles 291 of the Chilean Penal Code and 136 of the Act of Fishing and Aquaculture. We referenced the well-known Sanctuary of the Nature Carlos Anwandter Case (Valdivia), which has highlighted the factual and regulatory deficiencies in criminal-law protection of the environment in Chile.
\end{abstract}

\section{Key words}

Illegitimate statute of limitations, environmental criminal law, corporate crime

\section{Introducción.}

En la presente investigación se pretende abordar el estudio dogmático de los artículos 291 del Código penal (en adelante, "CP") y 136 de la Ley General de Pesca y Acuicultura. Estos preceptos forman parte de la escasa, asistemática y dispersa protección penal del 
MUÑOZ L., José; FERNÁNDEZ C., José Angel "Estudio dogmático penal de los artículos 291 del Código penal y 136 de la Ley General de Pesca y Acuicultura. A propósito del caso del Santuario de la Naturaleza Carlos Anwandter.

medio ambiente existente en Chile. ${ }^{1}$ A esta circunstancia de apatía o insuficiencia legislativa ${ }^{2}$ habría que añadir el, como se verá, reducido interés del Ministerio Público en la persecución de determinados casos concretos graves y en los que se encuentran implicadas grandes y poderosas empresas que, sin duda, tienen un notable grado de influencia en las instituciones públicas encargadas de la persecución de los delitos medioambientales. ${ }^{3} \mathrm{Si}$, además, a todo ello le agregamos la también exigua atención que la doctrina chilena ha prestado a dichos delitos, ${ }^{4}$ desembocamos en una clara conclusión: la deficitaria protección penal que para el medio ambiente existe en Chile y, como consecuencia, la limitada capacidad para hacer frente a los constantes riesgos que amenazan a este bien jurídico en las sociedades contemporáneas.

Ante tal panorama poco satisfactorio, el presente estudio tiene la clara finalidad de ofrecer unas bases dogmáticas sólidas y unas claves interpretativas claras para conseguir una aplicación práctica eficaz ${ }^{5}$ de la exigua normativa existente hasta la fecha en tanto los legisladores chilenos no se decidan a desarrollar de forma más exhaustiva la protección del medio ambiente a través del Derecho Penal. Para ello, y a la hora de establecer, analizar y solucionar los principales problemas dogmáticos y prácticos que presentan los arts. $291 \mathrm{CP}$ y 136 de la Ley de Pesca y Acuicultura hemos tomado como referencia el conocido caso de contaminación del Santuario de la Naturaleza Carlos Anwandter (Valdivia, Chile) también denominado Caso Celco, debido a la posible implicación de esta empresa

${ }^{1}$ Para hacerse una idea del actual estado de dispersión de la normativa de protección penal del medio ambiente en Chile, recogiendo una recopilación de las normas penales medioambientales, véase MATUS ACUÑA, Jean Pierre, "Fundamentos de la Propuesta de la Comisión Foro Penal para la Protección Penal del Medio Ambiente", Estudios Públicos $\mathrm{N}^{\circ} 110$ (2008), pp. 1 y ss., especialmente, pp. 17 y ss., accesible a través de la página web www.cepchile.cl

${ }^{2}$ A pesar de que el art. $19 \mathrm{n}^{\circ} 8$ de la Constitución chilena señale como una de las finalidades del Estado la protección del medio ambiente y a pesar, también, de la existencia de una propuesta de regulación penal sistematizada de delitos medioambientales preparada por la Secretaría Técnica de la Comisión Foro Penal e incluida en el Anteproyecto de Código Penal entregado al Presidente de la República el día 18 de diciembre de 2005. En mayor extensión sobre la misma véase MATUS ACUÑA, "Fundamentos de la Propuesta", cit. nota ${ }^{\circ} 1$, pp. 1 y ss.

${ }^{3}$ Hecho este que ocurre en todos los países. Un ejemplo de dicha influencia en España lo representa el caso Aznalcóllar. Al respecto, y en mayor extensión, véase BETANCOR RODRÍGUEZ/MUÑOZ LORENTE, "El caso Aznalcóllar: comentario al Auto de archivo de las diligencias desde las perspectivas jurídicoadministrativa y penal", Revista Interdisciplinar de Gestión Ambiental № 27, marzo de 2001, pp. 1 y ss.

${ }^{4}$ Con notables excepciones como la representada por MATUS ACUÑA. Así, entre los trabajos de este autor, cabe reseñar, por ejemplo, y sin ánimo exhaustivo: MATUS ACUÑA, Jean Pierre, (ed.): Derecho Penal del Medio Ambiente: estudios y propuestas para un nuevo Derecho Penal Medioambiental chileno, Santiago: Editorial Jurídica de Chile, 2004, obra que sentó las bases y fundamentos para la inclusión de los delitos medioambientales en el Anteproyecto de Código Penal citado en la nota anterior. También, del mismo véase MATUS ACUÑA, Jean Pierre (et alii), "Análisis dogmático del derecho penal chileno, a la luz del derecho comparado y las obligaciones contraídas por Chile en el ámbito del derecho internacional. Conclusiones y propuesta legislativa fundada para una nueva protección penal del medio ambiente en Chile", Ius et Praxis, vol. 9 , No 2 (2003), pp. 1-23

${ }^{5}$ Para que los pocos preceptos penales medioambientales existentes en Chile no se conviertan en Derecho Penal simbólico, esto es, delitos que se prevén para calmar las conciencias de políticos y ciudadanos pero que, en realidad, pocas o muy pocas veces se aplican. Al respecto, y en mayor extensión, véase MUÑOZ LORENTE, José, "Obligaciones constitucionales de incriminación y Derecho Penal simbólico", Revista de Derecho y Proceso Penal (Aranzadi) No 6 (2001), pp. 103 y ss. 
celulosa- ${ }^{6}$ que se ha convertido en una referencia a la hora de constatar las deficiencias en la protección del medio ambiente en Chile.

No obstante, y antes de centrarnos en el estudio dogmático de los citados preceptos, estimamos necesario realizar algunas consideraciones previas en relación con el supuesto de contaminación del Santuario Carlos Anwandter y su actual situación, para posteriormente enfrentarlo y subsumirlo en los preceptos penales que, en nuestra opinión, le son de aplicación.

\section{La prescripción y la decisión de no perseverar en la investigación como manifestaciones de la discriminación estructural del derecho penal.}

El presente estudio tiene como precedente un Informe en Derecho realizado por los autores de la presente investigación, que fue previamente solicitado por el Centro Patagónico de Derecho Ambiental y de los Recursos Naturales, relativo a los arts. 291 CP y 136 de la Ley de Pesca y Acuicultura en el procedimiento R.C.U. No: 0400438154-3 sobre los posibles responsables penales de la contaminación del Santuario de la Naturaleza Carlos Anwandter en el Río Cruces (Valdivia).

Tras la finalización de aquél Informe en septiembre de 2005, decidimos profundizar en su contenido y publicarlo como artículo doctrinal, debido a la ausencia de estudios dogmáticos sobre estos preceptos y su aplicación práctica a casos tan comunes como son los de contaminación hidrológica. También acordamos esperar a que la Justicia penal o en su defecto el Ministerio Público, tomara alguna decisión al respecto y, en especial, teníamos la esperanza de la celebración del juicio -a pesar de la alta probabilidad de que el proceso finalizara con algunas de las salidas alternativas recogidas en el Código procesal penal (en adelante, “CPP”)- ${ }^{7}$ para así poder complementar este estudio con un análisis y comentario de la sentencia.

\footnotetext{
${ }^{6}$ Debemos advertir que desde una perspectiva procesal penal no resulta correcto denominar Caso Celco, puesto que no existe ninguna formalización contra algunos de los miembros pertenecientes a esta empresa celulosa. Ahora bien, en otros órdenes jurídicos como el civil y administrativo resulta apropiado esta denominación, puesto que existe una demanda civil interpuesta por el Consejo de Defensa del Estado y la imposición de varias sanciones por parte de la Corema de los Región de los Ríos contra la citada empresa.

${ }^{7}$ Así, por ejemplo, un acuerdo reparatorio de los contemplados en los arts. 241-244 del CPP. No obstante, esta forma de finalización del proceso presenta el problema de concretar las víctimas en delitos que, como los medioambientales, protegen bienes jurídicos macrosociales o colectivos, también denominados difusos por pertenecer a una generalidad de ciudadanos indefinidos. Los denominados delitos sin víctimas o con víctimas indeterminadas suelen concurrir en el ámbito de los delitos socioeconómicos y ambientales, donde resulta $a$ priori imposible resarcir todos los daños -muchos de ellos indeterminados en el tiempo- y a todos los posibles perjudicados. Sin embargo, y aunque el art. 241 del CPP parece destinado a víctimas individuales, desde una interpretación más amplia del precepto, Duce y Riego entienden que en el mismo serían susceptibles de incluirse algunas hipótesis de resarcimiento a instituciones públicas o privadas que representaran a la comunidad y respecto de las cuales podrían acordarse fórmulas de reparación válidas. DUCE, Mauricio/RIEGO, Cristian: Proceso penal, Santiago: Editorial Jurídica de Chile, 2007, p. 340. No obstante, en estos últimos supuestos, sólo abarcarían las indemnizaciones civiles a la comunidad o grupos de personas perjudicadas, pero en ningún caso los daños estrictamente ambientales. Estos daños son de titularidad pública $y$, por definición excluidos de "aquellos que recaen sobre bienes jurídicos disponibles de carácter patrimonial". A este respecto, consideramos necesario indicar que en España, el problema de los daños estrictamente ambientales queda solventado ante la existencia para estos supuestos de una suerte de responsabilidad civil sui generis -prevista únicamente para los delitos medioambientales- contenida en el art.
} 
MUÑOZ L., José; FERNÁNDEZ C., José Angel "Estudio dogmático penal de los artículos 291 del Código penal y 136 de la Ley General de Pesca y Acuicultura. A propósito del caso del Santuario de la Naturaleza Carlos Anwandter.

Hasta la fecha de entrega del presente estudio a esta revista para su publicación previa la correspondiente evaluación, de forma ciertamente incomprensible habida cuenta del enorme tiempo transcurrido desde que acaecieron los hechos -más de 5 años-, el Ministerio Público no había finalizado la instrucción del procedimiento. Por esta razón, pronosticamos que la prescripción sería la encargada de solucionar jurídicamente este caso. Pero en octubre del 2010 durante el proceso de arbitraje de este estudio la Fiscalía adoptó finalmente una decisión: resolvió no perseverar en la investigación debido a la falta de antecedentes para fundar una acusación, finalizándose así la investigación conforme con los arts. 248 y 249 CPP; y ello, a pesar de la existencia de claros indicios racionales de criminalidad para formalizar la investigación que, sucintamente, pasamos a enumerar:

Así, en primer lugar, debemos destacar la existencia de un informe pericial realizado por la Universidad Austral de Chile, que determinó claramente que la causa de la contaminación del Santuario procedía de la celulosa CELCO y al que se hará referencia más adelante.

En segundo lugar, la imposición de varias sanciones administrativas impuestas por las autoridades en el mismo periodo en que se produjo el desastre ambiental en el Santuario. Así, CELCO fue sancionada en varias ocasiones por organismos como la Superintendencia de Servicios Sanitarios (en adelante, "SISS"), el Servicio de Salud de Valdivia y la Comisión Regional del Medio Ambiente (en adelante, "COREMA") de la Región de los Ríos.

En tercer lugar, tampoco debemos echar en saco roto la demanda civil interpuesta el 27 de abril del año 2005 por el Consejo de Defensa del Estado (en adelante, "CDE") en contra de la empresa CELCO, demanda que, a fecha de hoy, tampoco ha sido resuelta por el Tribunal

339 CP y distinta de la genérica responsabilidad civil deriva de delito. En efecto, dicho precepto contiene el denominado principio "quien contamina paga" en el sentido de que los Jueces y Tribunales ordenarán la adopción, a cargo del autor del hecho, de medidas encaminadas a restaurar el equilibrio ecológico perturbado; precepto que convive con la genérica responsabilidad civil derivada de delito. Conforme a esta última se indemniza a los particulares que hayan visto lesionados sus bienes patrimoniales como consecuencia de algún tipo de contaminación -lo que se denomina como "daños por contaminación"; y conforme al art. 339 el autor del hecho habrá de reparar, de ser posible, el equilibrio ecológico perturbado -los denominados "daños estrictamente ecológicos o ambientales"-. Al respecto, y en mayor extensión, véase MUÑOZ LORENTE, José, "La responsabilidad civil derivada de los delitos contra el medio ambiente y el alcance y contenido del artículo 339 del Código Penal: una regla de responsabilidad civil sui generis de los delitos medioambientales. Diferenciación entre los daños por contaminación y los daños estrictamente ecológicos", Revista Interdisciplinar de Gestión Ambiental $\mathrm{N}^{\circ} 25$, enero de 2001, pp. 47 y ss. Este precepto ha sido recientemente modificado el 9 de junio de 2010 -fecha en que el Senado español ha aprobado una extensa reforma del Código Penal- pero sin cambiar su esencia ni su naturaleza, es decir, el principio "quien contamina paga. La modificación ha consistido simplemente en hacerlo obligatorio; en otros términos, si antes del 9 de junio de 2010 eran los Jueces y Tribunales quienes, motivadamente, decidían si aplicar el principio o no, a partir de la reforma es obligatoria su aplicación. Un ejemplo de ello, lo tenemos estos días en el ámbito internacional: las emisiones de petróleo que se están produciendo en el Golfo de México como consecuencia del "accidente" de la petrolera British Petroleum (BP). Conforme al art. 339 -y de haberse producido este hecho en España- la petrolera no solo debería indemnizar a todo particular perjudicado -por ejemplo, los pescadores del litoral que ven reducidas sus capturas: "daños por contaminación" - sino asumir todos los gastos de limpieza del crudo hasta el momento en que el mar quede en su estado anterior al acaecimiento del "accidente" -"daños estrictamente ecológicos". 


\section{Polit. crim. Vol. 5, No 10 (Diciembre 2010), Art. 4, pp. 410 - 454. [http://www.politicacriminal.cl/Vol_05/n_10/Vol5N10A4.pdf]}

civil competente. El CDE ha fundamentado su postura en el "accionar negligente, desprolijo y reiterado de CELCO que, desde la misma entrada en operación de su Planta de Valdivia, realizó descargas ilegales y tóxicas al Río Cruces". Básicamente, el CDE busca que CELCO financie la restauración del ecosistema, un humedal protegido tanto por el Estado de Chile, como por la Convención de Ramsar sobre humedales de importancia internacional. Para ello el CDE debe demostrar la responsabilidad directa de la empresa del grupo ARAUCO en el desastre ambiental. En otros términos, algo similar a lo que está ocurriendo en estos momentos con la contaminación del Golfo de México como consecuencia de las actuaciones de la empresa British Petroleum (BP), con la salvedad de que, en este caso, ha sido la propia empresa quien desde el principio -y por presiones del Presidente Obama- ha procedido a reparar los daños; el tiempo dirá si, efectivamente, financiarán toda la restauración del ecosistema o si simplemente se trata de una maniobra de imagen de cara a la galería tanto de la propia empresa, como del Presidente Obama.

En cuarto lugar, los representantes de la empresa reconocieron en varios ocasiones que en la inicio de la actividades de la celulosa se cometieron varios errores.

Y por último, es preciso señalar cómo CELCO ha indemnizado a una gran parte de los perjudicados, sin ni siquiera, como hemos mencionado, haber sido formalizado algunos de los miembros de la citada empresa celulosa.

A pesar de que la investigación, como hemos comentado al inicio, haya finalizado por la decisión de la fiscalía de no perseverar en la investigación, entendemos conveniente mantener las consideraciones que realizamos sobre la prescripción, entre otras razones, porque esta decisión procesal no produce, por supuesto, cosa juzgada y, por lo tanto, es posible el inicio de otra investigación que finalice en una formalización que seguramente conllevaría a la discusión de la posible prescripción de la acción.

Estos claros indicios de criminalidad en el caso CELCO cuestiona abiertamente la inactividad del Ministerio Público. Si, definitivamente ha prescrito la acción -que de hecho podría ya entenderse prescrita- estaríamos ante un nuevo fracaso del Estado de Derecho, solución que constituye una costumbre en el tratamiento penal de las clases más poderosas en Chile. ${ }^{8}$ En fin, todos tenemos en la memoria, salvando las distancias, además de los crímenes cometidos bajo la dictadura de Pinochet, los casos de corrupción cometidos durante el Gobierno de la Concertación. En definitiva, y por lo que al medio ambiente se refiere, el poder económico de las grandes empresas hace que el medio ambiente se vaya degradando progresivamente y que éstas gocen de una intolerable impunidad, situación que socava la legitimación del Contrato Social.

\footnotetext{
${ }^{8}$ Por supuesto que esta situación no es sólo atribuible a Chile. A modo de ejemplo, en Italia, Pañazzo pone de relieve la existencia de un déficit real y grave de efectividad de la legislación penal especial italiana, que reside en la conjugación perniciosa entre la pobreza de tipología del aparato sancionatorio y la incidencia de toda una serie de causas extintivas de la responsabilidad penal, que van desde la suspensión condicional, el pago voluntario de una multa para evitar un proceso (oblazione), hasta la prescripción. PALAZZO, Francesco, C., "Per una razionalizzazione della legislazione complementare", Cassazione Penale $\mathrm{N}^{\circ} 1$, enero 2003, pp. 319 y ss.
} 
MUÑOZ L., José; FERNÁNDEZ C., José Angel "Estudio dogmático penal de los artículos 291 del Código penal y 136 de la Ley General de Pesca y Acuicultura. A propósito del caso del Santuario de la Naturaleza Carlos Anwandter.

Además de la falta de voluntad política de las Instituciones del Estado en la persecución penal, también concurren problemas de interpretación a la hora de aplicar la prescripción en los delitos ambientales. Dos son los más relevantes. El primero, radica en la especial dificultad de determinar el dies a quo (día que debe empezar el cómputo), y de manera especial en las acciones u omisiones crónicas o continuadas. ${ }^{9}$ El segundo problema, radica en los distintos plazos de prescripción de la normativa extrapenal ambiental que forman parte de los delitos ambientales estructurados como leyes penales en blanco. En estos casos, a efectos penales, el plazo de prescripción penal debe extenderse a las normas extrapenales.

Para solventar el cómputo de la prescripción de los delitos medioambientales podría existir una interpretación alternativa. En efecto, esa vía pasa por establecer que los delitos medioambientales de contaminación son "delitos permanentes", ${ }^{10}$ esto es, delitos en los que, realizando una ficción jurídica, se considera que la consumación se sigue renovando en el tiempo en tanto no cese la situación antijurídica. En consecuencia, y con independencia del momento de la comisión del hecho o de los hechos, ${ }^{11}$ el delito no comenzaría a prescribir hasta que no cesase la situación antijurídica de contaminación. ${ }^{12}$ Traducido esto a la figura central de este caso que nos ocupa (el art. 291 CP) significa que, con independencia del momento en el que se realizaron los vertidos, el plazo de prescripción no empieza a contar hasta que desaparezca el resultado (la propagación de agentes contaminantes) y el peligro para los bienes jurídicos protegidos (vida animal y vegetal y salud pública.

Pero volviendo al tema de la inactividad de las instituciones públicas en el caso Carlos Anwandter, resulta necesario señalar que no constituye el objeto de esta investigación abordar los factores políticos, sociales y económicos que han influido en esta inactividad del Derecho Penal -o mejor dicho, de las instituciones encargadas de velar por su aplicación-, pero debemos dejar claro que la contaminación del Santuario de la

\footnotetext{
${ }^{9}$ En estos casos, y respeto de la responsabilidad civil se ha propuesto una solución basada en establecer un criterio especial de aplicación temporal que atienda al momento del "conocimiento del daño" y no al momento de la comisión del daño. Véase, en el ámbito de la responsabilidad civil derivada de daños ambientales, Consejo Económico Social (España), Dictamen sobre el Anteproyecto de ley de Responsabilidad Civil derivada de Actividades con Incidencia Ambiental, 1999, en: http://www.ces.es/dictamenes/1999/dic0699.pdf [consultado el 28-5-2001].

${ }^{10} \mathrm{Y}$ así los ha interpretado el Tribunal Supremo Español. Al respecto, y en mayor extensión, véase MUÑOZ LORENTE, José, "El delito ecológico: su carácter de delito permanente y la interpretación de la agravación de clandestinidad", Revista Mensual de Gestión Ambiental N ${ }^{\circ}$ 7, julio de 1999, pp. 67 y ss.

${ }^{11}$ Conviene recordar que cuando se produce un atentado ecológico con significación penal éste no suele ser producto de una única acción u omisión, sino de una sucesión o pluralidad de actos u omisiones que, por separado, pueden o no da lugar también a un delito ecológico. Los atentados ecológicos suelen ser producto de la reiteración o acumulación de vertidos contaminantes; y ello particularmente ocurre cuando se llevan a cabo en el ámbito empresarial. En otros términos, los atentados medioambientales no suelen ser producto de un único vertido, sino de una sucesión de conductas semejantes que acaban por producir el resultado.

${ }^{12}$ Como expresamente establece el art. 132.1 del CP español y, salvo error u omisión por nuestra parte, no recoge expresamente el CP chileno. No obstante, habría que decir que las previsiones del CP español se encuentran recogidas en el mismo desde el año de 1995 y que, con anterioridad, la jurisprudencia interpretó que los delitos permanentes no iniciaban su plazo de prescripción en tanto no cesase la situación antijurídica. En este caso, el legislador español de 1995 no hizo otra cosa que recoger en el art. 132.1 la interpretación jurisprudencial.
} 
Naturaleza Carlos Anwandter supone una manifestación de exclusión de las clases más poderosas de control social. La discriminación social en el ámbito del sistema penal se presenta desde dos perspectivas. La primera, constata el hecho obvio de que las clases poderosas tienen una mayor facilidad de evitar, mediante medidas compensatorias o de otro tipo, situaciones embarazosas con el sistema penal sustrayéndose, por regla general, al mismo. ${ }^{13}$ La segunda, en palabras de Christie, pone en evidencia que:

“...todos los sistemas formales de control concentran su atención en determinados estratos de la población, que se encuentran a una cierta distancia de quienes detentan el poder. Los casos excepcionales en que una figura poderosa llega hasta al juez, [y en mayor medida si cumple efectivamente con la pena] son simplemente eso: casos excepcionales". 14

Dicho en otros términos, aún hoy sigue existiendo una Justicia penal de o para los pobres y una Justicia penal de o para los poderosos.

La prescripción fundamentada en el poder que ejerce la normativa y fácticamente las clases más poderosas constituye una manifestación del modelo penal liberal discriminatorio como rasgo definitorio de nuestro Sistema Penal. Este concepto puede ser tachado por algunos de tautológico, en el sentido de que el modelo penal liberal resulta per se discriminatorio. Ahora bien, este modelo toma como referencia dos niveles de discriminación presentes, al menos, en los modelos penales liberales: uno estructural y otro contingente.

Todo sistema social resulta estructuralmente discriminatorio ya que se fundamenta en un sistema de valores: quién adecúe más su conducta y proyecto de vida hacia esos valores tendrá más posibilidades de integrarse en este sistema social, y por ende, de recibir un reconocimiento; por el contrario, aquellos que se aparten de este sistema, y como mecanismo de supervivencia, ese sistema tenderá a erradicarlos o controlarlos.

Nuestro sistema social pivota normativa y fácticamente, entre otros, en el valor de la propiedad, y resulta estructuralmente necesario que todos los sistemas de control social, incluido el penal, se vean obligados a protegerla, es decir, las principales disfunciones estructurales de nuestro sistema social versan sobre los medios ilegítimos de acceso a la propiedad. A mayor abundamiento, la fase de incriminación primaria contempla un número importante de figuras penales destinadas a proteger la propiedad; la incriminación secundaria destina la mayor parte de sus recursos humanos (agentes policiales y judiciales) y materiales a este tipo delincuencia; y por último, y como consecuencia de lo anterior, nuestro sistema penitenciario está ideado para el delincuente patrimonial. Por el contrario, existen conductas que estructuralmente en un momento histórico determinado el sistema penal no está en condiciones de tipificar o aplicar. Son supuestos en que a la falta de una desvaloración social de la conducta se añade una especial relación con el poder político y

\footnotetext{
${ }^{13} \mathrm{Al}$ respecto, y en mayor extensión, véase MUÑOZ LORENTE, “Obligaciones constitucionales”, cit. nota $\mathrm{n}^{\circ} 5$, pp. 103 y ss.

${ }^{14}$ CHRISTIE, Nils, ¿La nueva forma del holocausto?, Buenos Aires: Editores del Puerto, Trad.: COSTA, Sara, 1993, p.126.
} 
MUÑOZ L., José; FERNÁNDEZ C., José Angel “Estudio dogmático penal de los artículos 291 del Código penal y 136 de la Ley General de Pesca y Acuicultura. A propósito del caso del Santuario de la Naturaleza Carlos Anwandter.

administrativo que conllevan a una inactividad legislativa o, en su defecto, de las agencias policiales, judiciales y penitenciarias.

El segundo nivel de discriminación abarca, en el ámbito del control penal, a aquellas manifestaciones político-criminales que afectan a principios y valores liberales que el propio sistema está en condiciones de superar. Así, y tomando por ejemplo, en la actualidad, el contexto político criminal chileno ha permitido una protección de la violencia intrafamiliar, que resultaba impensable en tiempos no demasiado alejados. Incluso, podemos estar ya en condiciones de articular una protección penal sistematizada del medio ambiente. Por supuesto, estos dos niveles de discriminación se encuentran en una constante relación dinámica, donde un determinado conflictos social puede trasladarse del primer nivel de discriminación al segundo de ellos.

La cuestión que se nos suscita ahora es en cuál de los niveles de discriminación debemos encuadrar el caso de la contaminación del Santuario de Valdivia. Antes de todo, debemos recordar que estamos ante un supuesto de ausencia de aplicación de varias normas penales. Aquí, la relevancia socioeconómica del holding al que pertenece la empresa CELCO y su especial relación con el poder político y administrativo nos lleva a pronosticar que estamos ante un caso de discriminación estructural, a pesar de que formalmente existan figuras penales como el art. $291 \mathrm{CP}$ e, incluso, medios materiales para llevar a cabo su aplicación. ${ }^{15}$ Inciden de manera especial en estos casos de discriminación estructural en la fase aplicación de las leyes penales, las propias deficiencias estructurales de las agencias policiales y judiciales para perseguir esta clase de delitos. ${ }^{16}$ Incluso, este tipo de prescripción estructural suele venir acompañado de un variopinto elenco de infracciones u omisiones administrativas y de delitos cometidos contra la Administración Pública y de Justicia, como pueden ser la prevaricación judicial y administrativa, la omisión de perseguir y aprehender delincuentes y todo tipo de obstrucciones a la Justicia. Y por último, el factor más importante viene dado por el denominado discurso de exclusión de las clases más poderosas.

Cuando un sujeto u organización perteneciente a las clases poderosas se encuentra ante la amenaza de una imputación penal suele articular un discurso propagandístico y populista dirigido a neutralizarla, y así ha ocurrido en caso Carlos Anwandter.

En efecto, en un estudio previo se ha estudiado cómo en el caso del Santuario de la Naturaleza de Valdivia la empresa CELCO, junto con el Gobierno y con la complicidad de determinados medios de comunicación, articularon un potente discurso a fin de mermar la desvaloración social de su posible responsabilidad, desprestigiando el estudio empírico

\footnotetext{
${ }^{15}$ Todo esto, sin perjuicio, de la insuficiente protección penal en el Sistema jurídico chileno. Véase, con mayor detenimiento, MATUS ACUÑA, “Análisis dogmático", cit. nota n 4, pp. 1-23.

${ }^{16}$ Así, la instrucción de este caso está siendo llevada por una Fiscal de una pequeña comuna (San José de la Mariquina), donde las deficiencias para perseguir este tipo de delincuencia medioambiental resultan patentes. En este sentido, debido a la extremada complejidad del caso hubiera sido conveniente el nombramiento de un Fiscal especializado en delitos ambientales o económicos. Que no se haya hecho constituye una muestra más de que políticamente no interesa la persecución del caso, esto es, discriminación estructural en la fase de aplicación de las leyes penales.
} 
realizado por la Universidad Austral de Chile y poniendo de manifiesto o, más bien, amenazando con las terribles consecuencias económicas y laborales que supondría "una respuesta jurídica desproporcionada". ${ }^{17}$ En cuanto al Gobierno, a modo de ejemplo, solo cabe destacar dos hechos sobre su participación en este discurso de exclusión. El primero fue el nombramiento de un ex-ministro del Gobierno de la Concertación para gestionar la crisis producida por la contaminación; y el segundo, con una cierta evocación escatológica, fue la conducta realizada por el Gobernador de Valdivia en esa época que, para certificar que el río y estuario no habían sido contaminados por la citada empresa, convocó a la prensa local para beber directamente agua de este río. Lo que olvidó el cargo público es que, debido a la cercanía a varios centros de población, el rio Valdivia contiene, entre otros contaminantes, aguas fecales. ${ }^{18}$

No obstante, la contaminación del Santuario y la atención que suscitó no sólo en la opinión pública, sino también en los operadores jurídicos, ha contribuido discursivamente a que en el futuro, ante un caso similar, nuestro Sistema Penal esté en condiciones de ofrecer una respuesta satisfactoria con el Estado de Derecho y a ello pretende contribuir el presente estudio. En otras palabras, estamos ante un conflicto social perteneciente al nivel estructural de discriminación que, en la actualidad, tiene visos de ser protegido penalmente (discriminación contingente).

\subsection{La facultad de no perseverar en la investigación del artículo 248 CPP.}

El día 8 de octubre de 2010, la Fiscalía encargada de la investigación decidió de nuevo no perseverar en la investigación, ${ }^{19}$ situación que ha llevado a la finalización de la investigación. La Fiscalía local manifestó: “previa consulta a la Fiscalía Regional de los

\footnotetext{
${ }^{17}$ Véase en extenso, FERNÁNDEZ CRUZ., José Ángel, "El Nuevo Código Penal: una lucha por el discurso de la criminalidad", Polit. crim. No 1 (2006), A5, pp. 1-30.

${ }^{18}$ Publicada en el Diario Austral el 11 agosto 2009. Que este hecho propagandístico y populista no es propio sólo de Chile, sino que se encuentra globalizado, se demuestra por un supuesto muy similar acaecido en España hace años pero que, aún hoy, se sigue recordando ya que los efectos perjudiciales del mismo para el medio ambiente, después de pasados más de 40 años, continúan aún presentes, como está científicamente demostrado (un estudio resumido se puede encontrar en http://marenostrum.org/ecologia/medio_ambiente/palomares/). Nos referimos al denominado caso Palomares. De manera resumida ocurrió lo siguiente: en el año de 1966, colisionaron en las costas españolas dos aviones de las fuerzas de EE.UU. Uno de ellos transportaba 4 bombas radiactivas que cayeron del avión en el momento del accidente. Dos de ellas explotaron y liberaron el contenido radiactivo y, oficialmente, las otras dos no lo liberaron. Con independencia de todo ello, por parte del Gobierno franquista se negó en rotundo la existencia de cualquier tipo de contaminación radiactiva. Es más, el entonces Ministro de Información y Turismo de Franco, Don Manuel Fraga Iribarne, acompañado de todos los medios de comunicación de la época, tuvo la osadía de bañarse en las aguas contaminadas para poner de relieve la ausencia de cualquier tipo de contaminación. En la actualidad todavía permanecen los comentarios jocosos sobre el traje de baño que lució el entonces Ministro, pero lo cierto es que, aún hoy, Don Manuel Fraga sigue vivo con alrededor de 90 años y con una salud de hierro. Si se nos permite la ironía, quizás sería conveniente investigar si, al contrario de lo que científicamente se cree, la contaminación radiactiva de las aguas no resulta perjudicial si no beneficiosa para salud y, un buen ejemplo, lo representaría Don Manuel Fraga.

${ }^{19}$ El fiscal de San José de la Mariquina, Alejandro Ríos Carrasco, en octubre de 2009, decidió no perseverar en la investigación, debido a que durante la investigación no se "reunieron antecedentes suficientes para formular una acusación” (sic). No obstante, el Juzgado de Garantía de San José de la Mariquina, el día 23 del citado mes, obligó a la reapertura de la causa, dando lugar a las solicitudes presentadas por los abogados querellantes. $\quad \mathrm{Al}$ respecto, en mayor extensión, véase: http://www.lanacion.cl/noticias/site/artic/20091102/pags/20091102203534.html
} 
MUÑOZ L., José; FERNÁNDEZ C., José Angel "Estudio dogmático penal de los artículos 291 del Código penal y 136 de la Ley General de Pesca y Acuicultura. A propósito del caso del Santuario de la Naturaleza Carlos Anwandter.

Ríos ha resuelto no perseverar en la investigación respecto de la contaminación del Santuario de la Naturaleza Carlos Anwandter, atendido que no existen "antecedentes para fundar una acusación”"”.

Esta facultad constituye, en principio, una actuación unilateral del Fiscal a cargo de la investigación, por lo que no procede que el Juez la apruebe o la rechace en la audiencia a que se refiere el artículo 249 CPP, cuyo único fin es darla a conocer. En efecto, se trata de una simple comunicación que, en uso de sus atribuciones legales, efectúa el Ministerio Público, referida a una decisión que sólo a él puede competer consistente en la decisión de no continuar con el procedimiento por no contar con antecedentes suficientes para intentar una acusación y un procedimiento serios ante el órgano jurisdiccional. ${ }^{20}$ Esta facultad puede utilizarse incluso cuando se trate de una investigación no formalizada pero sí judicializada, como sucede en nuestro caso. ${ }^{21}$

No obstante, los derechos que las partes pueden ejercer en esta audiencia, básicamente la víctima o el querellante que serían quienes eventualmente podrían verse en desacuerdo con la decisión del fiscal, se limitan a que la víctima puede ser oída por el fiscal, si lo ha solicitado, antes de que éste resuelva adoptar esta forma de terminación anticipada del procedimiento (artículo 109 letra d.- CPP). Respecto del querellante, la única posibilidad que se contempla a su respecto es la de solicitar al juez de garantía que lo faculte para sostener por sí mismo la acusación en los mismos términos que los establecidos para el Ministerio Público, a través del mecanismo del forzamiento de la acusación contemplado en el artículo 258 del Código de Procedimiento Civil (en adelante, "CPC"). No obstante, a pesar de no perseverar en la investigación, existe posibilidad de que pueda iniciarse una nueva investigación contra la misma persona y por los mismos hechos. ${ }^{22}$

A pesar de los indicios de criminalidad que hemos expuesto con anterioridad, resulta incompresible -o quizá se entienda demasiado bien- que la Fiscalía Regional no pudiera recabar los antecedentes necesarios para formalizar a los presuntos responsables. En todo caso, debemos reconocer la valentía de la Fiscalía de tomar una decisión al respecto y no dejar que el tiempo cure las heridas.

Tampoco hay que echar en caso roto la falta de fundamentación a la hora de decidir preservar con la investigación que, en este caso, se limita a citar los artículos respectivos del CPP.

\footnotetext{
${ }^{20}$ Oficio FN. $\mathrm{N}^{\circ}$ 556, "Facultad de los fiscales de no perseverar en el procedimiento, una vez cerrada la investigación", Santiago, noviembre 18 de 2003, p.4. No obstante, resulta frecuente que los Jueces de Garantía amplíen el plazo de la investigación si las partes ponen en evidencia que no se han practicado alguna prueba o diligencia necesaria para el esclarecimiento de los hechos.

${ }^{21}$ Sobre este punto también se puede consultar la sentencia dictada por la Iltma. Corte de Apelaciones de Antofagasta, con fecha 25/11/2004; Corte de Apelaciones de la ciudad de Temuco, con fecha 09 de febrero de 2005 , en recurso de apelación Ingreso $\mathrm{N}^{\circ} 78-2005$,

${ }^{22}$ En este sentido, HORVITZ, María Inés, Derecho Procesal Penal. Santiago: Editorial Jurídica de Chile, 2002 , pp. 586 y ss.
} 
Sobre esta posibilidad de sostener la acusación exclusivamente por el querellado en el ámbito de la gran criminalidad ambiental supone de facto una clara limitación a la protección de los justiciables, debido fundamentalmente a los costes de procesos (peritos, abogado, etc.) Y esta parece ser la razón por la que los querellantes desistieron de continuar la investigación contemplada en el citado art. 258 CPC.

Este mecanismo procesal pone de manifiesto las graves deficiencias de nuestro Sistema Procesal Penal a la hora de perseguir la criminalidad de los poderosos. ${ }^{23}$ En este sentido la propia Fiscalía Nacional añade otras razones: "Algunos expertos de la reforma procesal penal han comentado de que los fiscales han hecho un uso arbitrario de esta facultad, a veces por evitar las complejidades del juicio oral $y$ en otras ocasiones por no valorar suficientemente las posibilidades de éxito de la acusación en el juicio oral". ${ }^{24}$

Incluso la Fiscalía Nacional se hace cargo de los perjuicios que puede acarrear la facultad de no perseverar en los mal denominados delitos sin víctimas:

"El tema radica en la impresión que al resto de los intervinientes y a la ciudadanía en general le puede merecer la adopción de esta decisión por parte del Ministerio Público. Es evidente que, estando aún en una etapa preliminar en lo que es nuestro nuevo sistema de enjuiciamiento criminal, aún en implementación, resulta muy importante obtener la validación de la opinión pública y que la misma no estime que el Ministerio Público no está cumpliendo fielmente sus funciones y llevando a cabalidad las investigaciones que se le han confiado (por la propia Carta Política). Dentro de una modificación que, como muchas veces se ha repetido, no sólo es jurídica sino también cultural como lo es la Reforma Procesal Penal, es fundamental que la población no vea truncadas sus expectativas respecto de la labor de persecución penal que la Fiscalía realiza." 25

\section{El delito de propagación indebida de agentes contaminantes del artículo 291 CP.}

Al enfrentarse al estudio del precepto, lo primero que resulta necesario reseñar es que apenas ha sido aplicado por los Tribunales penales ${ }^{26} \mathrm{y}$, por esta razón, lo reproducimos para una mejor compresión del estudio dogmático a realizar:

"Los que propagaren indebidamente organismos, productos, elementos o agentes químicos, virales, bacteriológicos, radiactivos, o de cualquier otro orden que por su naturaleza sean

\footnotetext{
${ }^{23}$ A pesar de que la Fiscalía Nacional manifieste lo siguiente: "Con respecto al primer argumento, estimamos que el ejercicio de la facultad de no perseverar en el procedimiento no parece una demostración de inactividad por parte del órgano persecutor desde que éste reconoce la falta de antecedentes que le permitan fundamentar seriamente una acusación. En este sentido, cierra una investigación que no presenta buenas expectativas de éxito desde la perspectiva de la persecución penal sin que ello constituya una ineficiencia del sistema". Oficio FN. $\mathrm{N}^{\circ} 556, \mathrm{n} .21, \mathrm{p} .5$.

${ }^{24}$ Oficio FN. $\mathrm{N}^{\circ} 556$, n.21, p.6.

25 Oficio FN. $N^{\circ} 556$, n.21, p.7.

${ }^{26}$ A día de hoy, y salvo error u omisión por nuestra parte, no ha sido posible encontrar ningún fallo judicial que aplicara este precepto, aunque debemos tener presentes las deficiencias de los diferentes sistemas de búsqueda de jurisprudencia tanto públicas y privadas.
} 
MUÑOZ L., José; FERNÁNDEZ C., José Angel "Estudio dogmático penal de los artículos 291 del Código penal y 136 de la Ley General de Pesca y Acuicultura. A propósito del caso del Santuario de la Naturaleza Carlos Anwandter.

susceptibles de poner en peligro la salud animal o vegetal, o el abastecimiento de la población, serán penados con presidio menor en su grado máximo."

También, antes de adentrarnos en el estudio dogmático de las principales figuras aplicables, resumiremos sucintamente los hechos acaecidos:

- En mayo de 2004, después de 4 meses del inicio de la entrada en operación de la Planta de Celulosa Valdivia, propiedad de CELCO, se comenzó a hacer evidente que el Santuario de la Naturaleza Carlos Anwandter era víctima de uno de los desastres ecológicos más emblemáticos de la historia reciente del país.

- La señal más importante del desastre fue dada justamente por la muerte y migración masiva de las aves más emblemáticas del Santuario: los cisnes de cuello negro. Del promedio aproximado de 5.000 individuos que existieron en el Santuario en el año 2003, según datos de la Universidad Austral de Chile, a marzo de 2005, sólo quedaban 160 y las muertes registradas alcanzaban a 350 ejemplares. Esta cifra excluye a los individuos que pueden haber muerto en las zonas de poca accesibilidad del santuario (80\% del humedal), por lo que el total de muertes aumentaría al menos a 1000.

- El fenómeno causó alarma pública nacional y detonó la emergencia en la ciudad de Valdivia de un movimiento ciudadano sin precedentes que exigió explicaciones y medidas preventivas de un daño aún mayor. Ante las exigencias de la ciudadanía organizada y las pruebas del desastre que ésta había reunido, para mejor decidir y resolver, la Comisión Nacional del Medio Ambiente (en adelante, "CONAMA"), el organismo fiscalizador medioambiental, encargó a la Universidad Austral de Chile (en adelante, "UACH"), en noviembre de 2004, el Estudio sobre origen y mortalidad y disminución poblacional de aves acuáticas en el Santuario de la Naturaleza Carlos Anwandter en la provincia de Valdivia. Los propósitos del estudio fueron los siguientes: a) aclarar las causas de la muerte y migración de los cisnes de cuello negro del Santuario Carlos Anwandter, b) investigar la composición física, química y biológica de las aguas del Santuario del Río Cruces en las dimensiones temporal y espacial y c) investigar el origen de los cambios experimentados por el humedal (como sistema ecológico) y que originaron la muerte ó migración de los cisnes.

- Según las conclusiones del estudio de la UACH, los cisnes migraron y murieron por falta de alimento e intoxicación y su causa principal fue la disminución abrupta de la disponibilidad de su alimento principal, el luchecillo, así como el aumento episódico de metales pesados como Hierro y Aluminio en los sedimentos del Santuario. El aumento de sulfato de aluminio en la columna de agua causó la precipitación del hierro contenido en el agua a la superficie de las plantas, lo que interfirió en su proceso de fotosíntesis y finalmente causó su muerte.

- Del mismo modo, y a través de la cadena alimentaria, el metal fue traspasado a los cisnes y contribuyó a su intoxicación pues en los órganos de individuos muertos se encontraron cantidades significativas del metal. 


\section{Polit. crim. Vol. 5, № 10 (Diciembre 2010), Art. 4, pp. 410 - 454. [http://www.politicacriminal.cl/Vol_05/n_10/Vol5N10A4.pdf]}

- Puesto que el único factor antropogénico "nuevo" en el periodo en que se produjo el desastre ecológico fue el proceso industrial de fabricación de celulosa, que entró en operaciones en febrero de 2004, el equipo de científicos de la UACH decidió analizar la calidad de los efluentes vertidos por la planta de CELCO. El análisis que hace el estudio de la UACH de la calidad del agua en todos sus parámetros fisicoquímicos en varios lugares en la cuenca del Santuario, aguas arriba y aguas abajo de la descarga de la Planta de CELCO (con datos propios y de aquellos publicados por la empresa), constata que junto a sustancias autorizadas por la Resolución de Calificación Ambiental (en adelante, "RCA") de 1998 que aprobó la construcción y puesta en marcha de la planta, dicha industria también había vertido al Río Cruces sustancias no autorizadas por la RCA que incluyen Sulfatos, Cloratos y Aluminio, el cual causó la precipitación de Hierro soluble sobre las plantas, esto es, el metal pesado responsable de la muerte del luchecillo y los cisnes de cuello negro. Ahora bien, la RCA permitió la emisión de sustancias como las dioxinas, los furanos y los organoclorados -sustancias probadamente causantes de graves daños a la salud como el cáncer y mutaciones genéticas que afectan los sistemas inmunológico, reproductivo y nervioso-.

- El estudio de la UACH concluyó con que el régimen hidrodinámico de flujos del humedal y la magnitud de las descargas diarias realizadas por la planta de CELCO son incompatibles con la conservación del Santuario. ${ }^{27}$

\subsection{Tipicidad objetiva.}

El tipo objetivo del delito del art. $291 \mathrm{CP}$ tiene una estructura compleja. En primer lugar, muestra una configuración claramente resultativo en el plano físico-natural. Así, la conducta definida -la propagación - supone una producción de un resultado en el plano físico-natural. En segundo lugar, esta estructura resultativa físico-natural requiere la presencia de dos elementos normativos adicionales, para la perfecta consumación de esta figura delictiva: por una parte, la propagación debe haber sido indebida; y por otra, el resultado acaecido debe mostrar una virtualidad suficiente para poner en peligro la salud animal o vegetal, o el abastecimiento de la población. Véase, por tanto, que estamos ante un tipo penal de naturaleza compleja: ante un delito de resultado y de peligro. En otras palabras, nos enfrentamos ante un delito de resultado en cuanto al objeto de la acción y de peligro en cuanto al bien jurídico protegido, donde se requiere, en un primer momento, una relación de causalidad entre la conducta y el resultado físico-natural (la propagación), y posteriormente, un juicio normativo de imputación objetiva a dicho resultado de peligro para el medio ambiente, ${ }^{28}$ salvando las distancias, el precepto resulta tener una estructura

\footnotetext{
${ }^{27}$ Debe señalarse que no estamos ante hechos probados, sino ante hechos incluidos en el Informe científico de la Universidad Austral, resoluciones administrativas de la CONAMA y medios de comunicación. No obstante, en el ámbito de los delitos medioambientales los Informes científicos resultan ser, no sólo una prueba de enorme calado, sino una auténtica necesidad dado que, los jueces y tribunales no disponen de los conocimientos científicos suficientes como para prescindir de esos Informes y determinar, por ellos mismos, las causas exactas de lo acontecido.

${ }^{28}$ Así, en relación con el inciso primero del art. 325 del CP español, véase SILVA SÁNCHEZ, Jesús María, Delitos contra el medio ambiente, Valencia: Tirant lo Blanch, 1999, p. 24 El citado artículo señala: "Será castigado con las penas de prisión de dos a cinco años, multa de ocho a veinticuatro meses e inhabilitación especial para profesión y oficio por tiempo de uno a tres años el que contraviniendo las Leyes y otras
} 
MUÑOZ L., José; FERNÁNDEZ C., José Angel "Estudio dogmático penal de los artículos 291 del Código penal y 136 de la Ley General de Pesca y Acuicultura. A propósito del caso del Santuario de la Naturaleza Carlos Anwandter.

muy parecida a la del primer subtipo del art. 325 del CP español, aunque este último resulta mucho más prolijo y acabado. ${ }^{29}$

\subsubsection{Bien jurídico-penal protegido.}

El concepto de bien jurídico se utiliza por la doctrina penal en dos sentidos distintos: en primer lugar, en un sentido político-criminal como límite al poder punitivo del Estado, es decir, destinado determinar qué bienes jurídicos deben ser protegidos penalmente y de qué manera debe articularse su protección; y en segundo lugar, en un sentido típico o del injusto, como el objeto que efectivamente ha sido protegido por la norma penal. En el presente estudio sólo haremos referencia al objeto de la tutela jurídica.

El art. 291 CP está articulado como un delito pluriofensivo, esto es, como un delito que protege varios bienes jurídicos. En efecto por una parte protege la salud animal o vegetal y, por otra, la salud pública cuando el vertido afecte al abastecimiento de la población. Además, está estructurado como un delito alternativo, es decir, requiere para su consumación que se afecte sólo a uno de los tres bienes jurídicos protegidos. En el caso de que en un supuesto concreto se afecte a dos o a los tres bienes jurídicos deberá tenerse presente en la determinación de la pena conforme a lo establecido en el art. $69 \mathrm{CP}$. En este sentido, debemos recordar que una de las principales funciones dogmáticas del bien jurídico reside en la medición de la pena: la gravedad de la lesión o puesta en peligro del bien jurídico protegido influye decisivamente en su concreta determinación. ${ }^{30}$ Por último, todos esos bienes jurídicos son a la vez de naturaleza colectiva, es decir, pertenecientes a la generalidad de las personas que integran la comunidad. ${ }^{31}$

La propia dicción del precepto -sean susceptibles de poner en peligro- nos indica que grado de afección debe producirse en los bienes jurídicos protegidos. Esto es, para la consumación del tipo no resulta necesario que dichos bienes resulten lesionados, sino sólo puestos en peligro; no obstante, hay que tener en cuenta que, en los atentados medioambientales, en la práctica, y en la mayoría de los casos, los delitos se descubren cuando el bien jurídico ya ha resultado lesionado, pero ello no constituye ningún obstáculo

\footnotetext{
disposiciones de carácter general protectoras del medio ambiente, provoque o realice directa o indirectamente emisiones, vertidos, radiaciones, extracciones o excavaciones, aterramientos, ruidos, vibraciones, inyecciones o depósitos en la atmósfera, el suelo, el subsuelo, o las aguas terrestres, subterráneas o marítimas, incluido el alta mar, con incidencia incluso en los espacios transfronterizos, asi como las captaciones de aguas que puedan perjudicar gravemente el equilibrio de los sistemas naturales. Si el riesgo de grave perjuicio fuese para la salud de las personas, la pena de prisión se impondrá en su mitad superior". Transcribimos el precepto tal y como ha sido redactado tras la reforma del Senado de 9 de junio de 2010 y que, a fecha de hoy, todavía no ha sido publicado en el Boletín Oficial del Estado español. La reforma del precepto sólo se ha centrado en aumentar la pena privativa de libertad y en introducir la referencia a "el alta mar" como consecuencia de las obligaciones asumidas por España y derivadas de la normativa de la Unión Europea.

${ }^{29}$ Véase la nota anterior

${ }^{30}$ Por todos, en este sentido, véase MIR PUIG, Santiago, Derecho penal. Parte general, ( $6^{\circ}$ ed.) Barcelona: Reppertor, 2002, p.166.

31 Por todos, MARTÍNEZ-BUJÁN PÉREZ, Carlos, Derecho penal económico. Parte general, Valencia: Tirant lo Blanch, 1998, p. 95.
} 
para que podamos seguir hablando de un delito de peligro. Así, por ejemplo, y centrándonos en el supuesto del caso del Santuario de Valdivia, el delito se descubrió por la existencia de cisnes muertos; la salud de estos animales no sólo fue puesta en peligro, sino lesionada. Pero ello no significa que no estemos ante un delito del art. 291 del CP en el hipotético caso de que no se hubiese producido la muerte de ningún cisne; antes al contrario, si se hubiese comenzado a investigar antes de descubrir cualquier animal muerto, también sería posible afirmar la existencia de delito si se hubiese probado el peligro para su salud. En definitiva, en delitos de peligro como este, el legislador adelanta las barreras punitivas a momentos anteriores a la lesión del bien jurídico declarando el delito consumado cuando sólo existe peligro para el bien jurídico. Ahora bien, queda por dilucidar ante qué clase de delito de peligro nos encontramos y la intensidad de este peligro, cuestiones que abordaremos en un apartado posterior.

No obstante, conviene preguntarse si en el caso CELCO se ha producido una puesta en peligro del bien jurídico protegido. Lo cierto es que debemos responder afirmativamente a esta cuestión porque, en dicho supuesto, no sólo se puso en peligro el medio ambiente, sino que resultó lesionado. El gran número de ejemplares de cisne negro muertos avalan esa conclusión. Según el Informe científico de la UACH fueron 350 ejemplares muertos con la posibilidad de que, en realidad, esa cifra llegase a 1.000 dado que no se pudo acceder al $80 \%$ del humedal. En este caso no se puede hablar de peligro para la salud animal, sino que la vulneración del bien jurídico se encuentra en un estadio superior: el de lesión de la salud y vida animal además de la vegetal. En efecto, no olvidemos que los vertidos también produjeron la desaparición del luchecillo que era el alimento de los cisnes y que por eso se vieron obligados a migrar o murieron como consecuencia de la ingestión de la planta que contenía sustancias químicas fruto de los vertidos como determinó el Informe científico de la $\mathrm{UACH}$ al que ya se ha hecho referencia.

\subsubsection{El delito de propagación indebida y su naturaleza de ley penal en blanco.}

El art. 291 CP se encuadra dentro de lo que se denomina como Derecho penal del riesgo. Conforme a concepto socio-jurídico, lo que se pretende proteger son unos bienes que la sociedad ha aceptado poner en peligro en aras de conseguir unos determinados fines sociales. Sin la puesta en peligro de determinados bienes jurídicos es muy difícil que la sociedad se siga desarrollando conforme con los actuales niveles de crecimiento económicos. Las relaciones entre la necesidad de protección y la consecución de estos finales sociales de desarrollo -que, por lo que al medio ambiente se refiere se ha de concretar en un desarrollo sostenible- se articulan a través de la inclusión en la estructura típica del delito de remisiones normativas expresas o tácitas a aquellas ramas del ordenamiento jurídico que protegen y regulan directamente estas relaciones sociales. En este sentido, la remisión expresa o tácita a esa normativa extrapenal no hace otra que establecer aquellos supuestos en los que el riesgo se encuentra permitido y aquellos otros en los que lo sobrepasa, que en este último supuestos se ocupa el Derecho administrativo sancionador y, como ultima ratio, el Derecho penal.

Para un mejor entendimiento, pongamos un ejemplo relacionado con el medio ambiente. Es evidente que en las actuales sociedades resulta necesario realizar vertidos, ya domésticos, 
MUÑOZ L., José; FERNÁNDEZ C., José Angel "Estudio dogmático penal de los artículos 291 del Código penal y 136 de la Ley General de Pesca y Acuicultura. A propósito del caso del Santuario de la Naturaleza Carlos Anwandter.

ya industriales. $\mathrm{Y}$ esos vertidos están regulados y autorizados por la normativa administrativa aun a riesgo de que puedan poner en peligro -e incluso lesionar- el medio ambiente (es lo que se denomina como ecocriminalidad legalizada). ${ }^{32} \mathrm{Si}$ los vertidos se realizan de manera conforme a dicha normativa nunca pueden constituir un ilícito penal ya que lo que autoriza una parte del Ordenamiento no lo puede prohibir otra. Ahora bien, sí constituirán delito cuando esos vertidos se realicen de forma contraria a dicha normativa porque, en ese caso, ya no nos encontraríamos ante un riesgo permitido, sino ante uno no permitido o también denominado incremento del riesgo. Cuando dicho incremento del riesgo no es grave, normalmente se prevén sanciones administrativas; si ese incremento se considera grave, entonces es cuando ha de intervenir el Derecho Penal.

Precisamente, el término "indebidamente" recogido en el art. 291 del CP constituye una de esas referencias a la normativa extrapenal que, en ciertos casos, permite realizar vertidos y en otros no. $\mathrm{O}$, dicho de otro modo, para entender consumado el tipo se requiere una previa vulneración de una norma extrapenal, normalmente una norma administrativa. Pero, lo cierto es que ese término no podemos circunscribirlo de manera exclusiva a una norma escrita extrapenal, sino también, a la costumbre profesional (Lex artis). Por esta razón, el citado precepto se sitúa entre un tipo abierto y una ley penal en blanco. No obstante, debido al proceso de normativización de los nuevos ámbitos de riesgo en las sociedades contemporáneas, en la mayoría de los casos existirá una norma extrapenal de carácter administrativo.

Por tanto, la vulneración de una norma extrapenal relacionada con la salud animal, vegetal y pública constituye un elemento objetivo del tipo penal, que, en caso contrario fundamenta una causa de atipicidad, sin perjuicio de la responsabilidad que pudiera concurrir en los miembros de la Administración que hayan autorizado una actividad peligrosa para el medio ambiente de manera contraria a dicha normativa extrapenal. ${ }^{33}$ En otros términos, un vertido realizado de manera conforme a la normativa administrativa no es un vertido realizado "indebidamente" y, por tanto, no es delictivo.

\footnotetext{
${ }^{32}$ En mayor extensión sobre esa denominación, véase MUÑOZ LORENTE, “Obligaciones constitucionales", cit. nota $\mathrm{n}^{\circ} 5$, pp. 103 y ss.

${ }^{33}$ El CP español en su art. 329 ha incluido un tipo de prevaricación específica en relación con la intervención de las Administración en la concesión de licencias manifiestamente ilegales que autoricen industrias contaminantes o, la omisión por parte de ésta de las infracciones que hubiera cometido en el ejercicio de su labor inspectora. También se castiga a los miembros de un organismo colegiado que hubiese votado a favor de una concesión a sabiendas de su injusticia. Véase en extenso y los problemas interpretativos de esta figura en CANCIO MELIÁ, Manuel.: "La responsabilidad del funcionario por delitos contra el medio ambiente en el Código Penal español", $A D P C P$, Vol. LII (1999), pp. 137-176. No obstante, a pesar de no contar con esta figura en el Sistema penal chileno, la denominada prevaricación administrativa recogida en los arts. 288 y 289 CP puede aplicarse a estos supuestos. En concreto el art. $288 \mathrm{CP}$ castiga la dictación de providencia o resolución manifiestamente injusta por parte de funcionarios públicos. En sentido debemos recordar que el término "resolución" en a efectos penales no debe coincidir con el establecido en el derecho administrativo, sino que comprende toda manifestación de voluntad de contenido decisorio. En el mismo sentido, el término de "negocio meramente administrativo" constituye un concepto residual que permite abarcar todos los asuntos no judiciales, políticos o de Gobierno. También, debemos recalcar que el precepto citado en su último inciso recoge un tipo imprudente (grave). Véase, RODRÍGUEZ COLLADO/OSSANDÓN, Delitos contra la Función Pública ( $2^{\circ}$ ed.), Santiago: Editorial Jurídica de Chile, 2008, pp. 443 y ss.
} 
El término indebidamente plantea, además, la interesante cuestión de si la mera existencia de un acto administrativo - una licencia administrativa, por ejemplo-, pero que vulnera normas extrapenales, puede fundamentar la atipicidad de la conducta. Entendemos que dicha autorización no puede excluir automáticamente la tipicidad objetiva, si dicho acto vulneró disposiciones generales y existe conocimiento de esta irregularidad. Cuestión distinta es el conocimiento que tuviera el sujeto activo de la irregularidad de la licencia administrativa que podría dar lugar a un error de tipo ya vencible, ya invencible, dependiendo de los casos. No obstante, en estos supuestos de licencias ilícitas sí resultaría posible exigir responsabilidad a los miembros de la Administración Pública que a sabiendas dictaron un acto administrativo en contra de las normas generales protectoras del medio ambiente. $^{34}$

¿Realizó CELCO vertidos “indebidamente”? En nuestra opinión, la respuesta no puede ser más que afirmativa. Y esta circunstancia viene avalada por el hecho de que, como ya se señaló, diversos órganos administrativos le impusieron varias sanciones por los vertidos realizados ya que varias de las sustancias vertidas al río y encontradas en el mismo no fueron objeto de autorización por la Resolución de Calificación Ambiental de 1998 que aprobó la construcción y puesta en marcha de la planta. Esto es, CELCO, a la hora de realizar los vertidos, se excedió de lo que tenía administrativamente autorizado y eso supone que nos encontramos ante vertidos realizados "indebidamente" tal y como establece el art. $291 \mathrm{del} \mathrm{CP.}$

A este respecto, queda una única cuestión por analizar y es la de la legalidad de los vertidos objeto de autorización por la Resolución de Calificación Ambiental de 1998. Dicho en otros términos ¿esa autorización cumplía con la normativa vigente? Nos planteamos esta cuestión porque, como revela el Informe científico de la UACH, dicha Resolución autorizó la realización de vertidos de sustancias como dioxinas, furanos y organoclorados, sustancias todas ellas potencialmente muy peligrosas para la salud y susceptibles de causar enfermedades como el cáncer y mutaciones genéticas que afectan a los sistemas inmunológico, reproductivo y nervioso. No tenemos ningún dato que revele que la Resolución era contraria a lo que establece la normativa administrativa; ahora bien, resulta curioso que la normativa administrativa resulte tan laxa con el vertido de sustancias tan tóxicas y perjudiciales tanto para la salud humana como para la animal y vegetal. En caso de que dicha Resolución no se hubiese ajustado a lo establecido en la normativa administrativa ya podríamos plantearnos la posibilidad de la existencia de un delito, bien de prevaricación, bien medioambiental o, hasta incluso, y de darse el caso, de cohecho. Ante la falta de datos sobre este extremo no podemos pronunciarnos más claramente.

\subsubsection{La conducta típica del art. 291 del CP.}

La conducta típica consiste en la propagación de determinadas sustancias. En este sentido, resulta necesario hacer notar que la descripción típica se refiere específicamente a la naturaleza de algunas sustancias (radiactivas, bacteriológicas, químicas, etc. Pero esta enumeración no debe calificarse como un catálogo cerrado, esto es, puede tratarse de

\footnotetext{
${ }^{34}$ SILVA SÁNCHEZ, Delitos contra el medio ambiente, cit. nota $n^{\circ} 28$, p. 78.
} 
MUÑOZ L., José; FERNÁNDEZ C., José Angel "Estudio dogmático penal de los artículos 291 del Código penal y 136 de la Ley General de Pesca y Acuicultura. A propósito del caso del Santuario de la Naturaleza Carlos Anwandter.

cualesquiera otras sustancias que por su naturaleza puedan ser consideradas como "contaminantes" o, tal y como establece el tipo, que por su naturaleza sean susceptibles de poner en peligro a los animales, plantas, o la salud pública por afectar al abastecimiento de una población.

Estamos ante un delito resultativo que permite tanto la acción como la omisión; respecto de esta última nos ocuparemos en extenso más adelante. Como hemos manifestado, la propagación supone una producción de un resultado en el plano físico-natural, por ejemplo, un vertido, de organismos, productos, elementos o agentes químicos, virales, bacteriológicos, radiactivos, o de cualquier otro orden que haya causado una propagación de éstos. Y esas circunstancias se pueden dar, bien mediante una acción - por ejemplo, abrir el grifo para que salga el vertido- o mediante una omisión - por ejemplo, no reparar una cañería que se sabe que está en mal estado y que, en caso de romperse puede producir unos vertidos o no cumplir con las medidas de seguridad adecuadas para evitar la producción de un vertido-.

En el caso de CELCO, y a falta de mayores datos, nos encontramos ante una conducta activa de realización de vertidos -de propagación de sustancias- ya que no consta en ningún lugar que los vertidos se realizasen como consecuencia de un "accidente" o mal funcionamiento de la planta o por no haber cumplido la planta con las medidas de seguridad establecidas.

\subsubsection{La relación de causalidad.}

Hemos recalcado la necesidad de que se produzca un resultado físico natural, es decir, un vínculo -conforme a las leyes de la experiencia científica- que establezca una relación entre la conducta del agente y la propagación de sustancias contaminantes. Con posterioridad, deberá realizarse un juicio normativo de imputación de riesgos sobre los bienes jurídicos protegidos, que se examinará más adelante (véase el epígrafe relativo a la imputación objetiva). Obsérvese como este proceso de constatar que la conducta del agente causó la propagación es previo a cualquier posible imputación comisiva u omisiva posterior. Aquí se trata de determinar la fuente físico-natural de la propagación, y posteriormente, sobre este juicio de causalidad deberán realizarse los juicios de imputación comisiva u omisiva -esto es, si se debió a una acción u omisión del sujeto-y la imputación subjetiva.

Una vez dentro del marco normativo de la tipicidad, la afirmación de que una acción ha causado el resultado no es más que un presupuesto a partir del cual hay que seguir preguntándose si esa causación del resultado es objetiva o normativamente imputable a la acción causal del sujeto. A modo de ejemplo, en el ámbito de una actividad industrial, será frecuente que quién realice materialmente el vertido no tenga responsabilidad penal -por ejemplo, el concreto empleado subalterno de la factoría que, cumpliendo órdenes, abre el grifo de la tubería por el que salen las sustancias tóxicas,$-{ }^{35}$ pero la determinación causal

\footnotetext{
${ }^{35}$ Más ampliamente, en relación con esta cuestión, véase MUÑOZ LORENTE, José, "Nula concreción por parte de la acusación de la norma administrativa vulnerada e integrante del delito ecológico del artículo 325 del Código Penal. La exención de responsabilidad por delito ecológico de los empleados subalternos que
} 


\section{Polit. crim. Vol. 5, No 10 (Diciembre 2010), Art. 4, pp. 410 - 454. [http://www.politicacriminal.cl/Vol_05/n_10/Vol5N10A4.pdf]}

entre su acción material y el resultado de propagación será fundamental para imputar normativamente este resultado a terceras personas a título de autoría mediata o de comisión por omisión. ${ }^{36}$

Este punto de vista que trata la causalidad como mero presupuesto sobre el que apoyar el juicio de imputación objetiva de resultado, implica, obviamente, que la causalidad se define por sus caracteres estrictamente naturales, y los ulteriores criterios restrictivos de esa causación son elementos normativos de imputación objetiva de resultado. Dentro de los elementos del tipo objetivo se camina, pues, desde la causación del resultado hasta la imputación objetiva del mismo. La relación de causalidad es, pues, el presupuesto sobre el que se apoya el juicio de imputación objetiva del resultado.

A partir del presupuesto de que es causa de un resultado toda la acción que aparece unida a él según las leyes naturales, la doctrina suele trivializar sobre la dificultad que a veces comporta su investigación. Además, en los últimos decenios se ha renovado la importancia penal sobre los problemas de causalidad general y concreta. La razón estriba en las consecuencias derivadas de la denominada "sociedad del riesgo". En efecto, desde mediados del siglo pasado estamos ante una eclosión tecnológica y científica que ha supuesto la creación de nuevas actividades que, si bien pueden ser beneficiosas para la sociedad, conllevan un importante riesgo para determinados bienes jurídicos que el modelo social considera esenciales. La protección del medio ambiente constituye el ejemplo paradigmático, donde la determinación de la relación de causalidad es uno de los aspectos centrales de la tipicidad y en la prueba y fundamentación de los hechos.

Para la determinación de la causalidad general hay que tener en cuenta las siguientes precisiones:

a) Las leyes causales naturales aseguradas científicamente y admitidas generalmente por los especialistas constituyen principios de experiencia obligatoria, en el sentido de que tienen que ser necesariamente atendidos judicialmente. Así, y en el tema que nos ocupa, debe establecerse si la emisión de grandes cantidades de sulfato de aluminio a un estuario es admitida por la generalidad de los especialistas como un supuesto de propagación de agentes químicos.

b) El problema surge cuando la prueba científica no está asegurada, sino que es cuestionable entre especialistas. ${ }^{37}$ En tales casos suele acudirse a la "certeza subjetiva" de la causación que proporciona al juez la prueba penal, aunque no se llegue a "certeza objetiva" de la prueba científica. Esta es una cuestión que debe someterse a límites precisos, puesto que la causalidad general sólo puede afirmarse cuando existe una aceptación general

materialmente realizan los vertidos objeto del delito", Revista Mensual de Gestión Ambiental № 22, octubre de 2000, pp. 39 y ss.

${ }^{36}$ SILVA SÁNCHEZ, Delitos contra el medio ambiente, cit. nota ${ }^{\circ} 28$, p. 65.

37 Algo que suele ocurrir de manera muy común en el ámbito de los delitos contra el medio ambiente dado que las grandes empresas implicadas en ellos tienen el suficiente potencial económico como para encargar Informes o Dictámenes científicos de parte que tienen como misión cuestionar abiertamente los Informes que les incriminan. 
MUÑOZ L., José; FERNÁNDEZ C., José Angel “Estudio dogmático penal de los artículos 291 del Código penal y 136 de la Ley General de Pesca y Acuicultura. A propósito del caso del Santuario de la Naturaleza Carlos Anwandter.

científica, ya que se trata de una cuestión estrictamente científico-natural. La convicción subjetiva de una relación causal no puede, pues, ser suficiente cuando científicamente la ley causal no está generalmente admitida. A modo de ejemplo, en el ámbito medioambiental en la actualidad se encuentra en cuestión, esto es, no existe una aceptación científica general sobre si las radiaciones no ionizantes emitidas por las antenas de telefonía móvil son o no perjudiciales para la salud. Un sector de los científicos estima que sí y otro sector posiblemente más cercano a las empresas de telefonía- niegan tal perjuicio. Quizás en el futuro, y con mayores adelantos científicos, sea posible lograr una aceptación general científica al respecto como ha ocurrido, por ejemplo, con el tabaco: en los años 50-60 del siglo XX se empezaron a plantear por parte de científicos independientes los posibles efectos perjudiciales para la salud; las tabacaleras, especialmente de EE.UU., negaron tales efectos a través de Informes científicos de manera que lograron que no existiera una aceptación general científica sobre los efectos del tabaco en la salud. Sin embargo, en la actualidad sí existe esa general aceptación científica sobre los efectos de dicha sustancia.

c) Un problema que puede acontecer también en la relación a la causalidad general del medio ambiente es el derivado de las denominadas leyes causales imperfectas, que se caracterizan porque se conoce la causalidad general de determinada acción o producto en determinadas circunstancias, pero se desconocen algunos eslabones del curso causal. Incluso, las leyes de causalidad general permiten acceder, a veces, a la certeza de la relación de causalidad. Así, si el efecto " $\mathrm{X}$ " se produce en las circunstancias " $\mathrm{A}+\mathrm{B}+\mathrm{C}$ ", pudiéndose constatar la concurrencia de las circunstancias "A" y " $\mathrm{B}$ ", y desconociéndose el último eslabón "C", el curso causal puede afirmarse como existente, a no ser que se formule otra hipótesis capaz de refutar ese fenómeno desconocido. ${ }^{38}$

Recientemente la cuestión de la causalidad general ha motivado un renacimiento en la reflexión jurídica -no sólo en el ámbito penal sino también en derecho civil- en torno a si este criterio de imputación puede llegar a ser prescindible o, a lo sumo, reformulado conceptualmente. En este contexto parece imponerse la comprensión de la causalidad como una cierta regularidad existente entre sucesos observables del mundo físico. En este sentido, Héctor Hernández en la doctrina chilena entiende que la prueba penal -incluida la relativa a la causalidad-nunca funciona sobre la base de certezas, sino sólo con grados más o menos altos de plausibilidad o probabilidad, como lo demuestra el rol prominente que posee la denominada prueba indiciaria en las prácticas probatorias. ${ }^{39}$

Así, las ciencias naturales realizan explicaciones de la realidad de tipo probabilística a través de una correlación estadística; es lo que algunos sectores denominan como "causalidad estadística". En este contexto, juega un papel fundamental la exclusión de las posibles causas alternativas del resultado, en el sentido de que el factor investigado se convierta en la única explicación del resultado. Ahora bien, esto no significa exigir el conocimiento de todas las posibles causas o factores, debido al carácter incompleto y

\footnotetext{
${ }^{38}$ Por todos, GÓMEZ BENÍTEZ, José Manuel, Teoría jurídica del delito. Parte general, Madrid: Civitas, 1992, p.163 y ss.

${ }^{39}$ Véase, HERNÁNDEZ, Héctor, "El problema de la "causalidad general" en el derecho penal chileno (con ocasión del art. 232 del Anteproyecto de Nuevo código Penal)", Polít. crim. $\mathrm{N}^{\circ} 1$ (2006), A7, p. 19.
} 


\section{Polit. crim. Vol. 5, No 10 (Diciembre 2010), Art. 4, pp. 410 - 454. [http://www.politicacriminal.cl/Vol_05/n_10/Vol5N10A4.pdf]}

provisorio del conocimiento científico, sino del conocimiento de los factores que sean conocidos y que científicamente se les pueda atribuir influencia en la producción del resultado. ${ }^{40}$

Héctor Hernández, por último, hace referencia a la denominada causalidad epidemiológica desarrollada por la jurisprudencia japonesa en el ámbito de la responsabilidad médica y que posee una similar estructura a la establecida en la causalidad probabilística, estadística o de exclusión. Sus principales presupuesto son los siguientes: a) que el factor haya aparecido con anterioridad a la enfermedad; b) que el número de enfermos aumente cuando la incidencia del factor aumenta; c) que los afectados sólo aparecen en el ámbito de incidencia del factor; y d) que las ciencias naturales aporten una explicación sobre el mecanismo biológico desencadenado por los efectos del factor. ${ }^{41}$ Estos criterios son perfectamente extrapolables a los casos de contaminación.

No obstante, el procedimiento de exclusión ha sido objeto de críticas -compartidas por el autor- en el sentido de qué solo nos aporta que el resultado ha sido causado de algún modo, pero no arroja información sobre cómo lo ha causado lo que, términos dogmáticos, transformaría los delitos de lesión en delitos de peligro. ${ }^{42}$ Ahora bien, esta crítica debe ser matizada en el sentido de que a pesar de que la relación de causalidad desde una perspectiva probabilística genera un cierto juicio de peligro, no debemos olvidar que los delitos de resultado, valga la redundancia, exigen un resultado típico. En otras palabras, no resultan equiparables a los delitos de peligro donde no se exige una efectiva lesión del bien jurídico protegido.

Sobre la base de esa "causalidad general" se construye la "causalidad concreta", o determinación de la causación del resultado en las concretas circunstancias del hecho, pues la causalidad típica no sólo es una causalidad general, sino que exige la afirmación del nexo causal concreto entre la conducta del sujeto, las circunstancias del hecho, y el resultado acaecido.

\footnotetext{
${ }^{40}$ HERNÁNDEZ, "El problema", cit. nota n 39, p. 23. Véase la copiosa bibliografía citada por el autor.

${ }^{41}$ No obstante, es necesario precisar cómo en Europa, desde hace tiempo, ya se ha empleado ese mismo criterio aunque denominándolo como causalidad estadística. En efecto, ello ocurrió en Alemania con el conocido como caso Contergan y en España con el caso del aceite de colza. Muy resumidamente los hechos del caso Contergan son los siguientes: la empresa Contergan fabricaba un medicamento -talidomida- para evitar las náuseas de las embarazadas. Se observó que muchas de las mujeres que habían ingerido el medicamento tuvieron hijos muertos o con graves malformaciones; otras, sin embargo, tuvieron hijos totalmente sanos. ¿Era la talidomida la causa de esas malformaciones? ¿o era la talidomida más la unión de algún otro factor desconocido la que produjo esas malformaciones? En el caso del aceite de colza desnaturalizado ocurrió algo similar: su ingestión produjo muertes y enfermedades a muchas personas que lo ingirieron pero otras, incluso dentro de una misma familia, no tuvieron ningún síntoma. ¿Era el aceite de colza el causante de esos efectos? ¿o era el aceite de colza más la unión de algún otro factor desconocido? Científicamente, en ningún de los dos casos se pudo llegar a afirmar científicamente que esos factores habían producido las secuelas, existía una alta probabilidad de que así fuese pero no se podía afirmar rotundamente por parte de los científicos. Sin embargo, para resolverlo y afirmar la existencia de relación de causalidad, se utilizó la denominada "causalidad estadística": puesto que un buen número de personas habían estado relacionadas con el factor -talidomida/aceite de colza- se llegó al convencimiento de que esos factores habían sido los causantes de los resultados.

${ }^{42}$ HERNÁNDEZ, "El problema", cit. nota n 39, p.29.
} 
MUÑOZ L., José; FERNÁNDEZ C., José Angel "Estudio dogmático penal de los artículos 291 del Código penal y 136 de la Ley General de Pesca y Acuicultura. A propósito del caso del Santuario de la Naturaleza Carlos Anwandter.

Dentro de la investigación de la causalidad concreta se presentan distintos cursos causales problemáticos, y en especial los denominados cursos causales complejos. Estos tienen lugar cuando el resultado obedece a una acumulación de causas; junto a una causa inmediata pueden concurrir causas precedentes y sobrevenidas. En el ámbito de la contaminación resulta posible la concurrencia de los denominados cursos causales complejos por acumulación de causas, donde puede resultar problemática la determinación de la fuente que ha producido el resultado. Pero debemos de nuevo afirmar que estos problemas en el ámbito del art. $291 \mathrm{CP}$, deben circunscribirse exclusivamente en la propagación y no a otras causas posteriores, como la desaparición del lucecillo o la muerte o migración de los cisnes de cuello negro. ${ }^{43}$ Es decir, deberá determinarse si la existencia de grandes cantidades de sulfato de aluminio en el Estuario Carlos Anwandter procede de una o diversas causas o fuentes. En este sentido, y si atendemos al Informe científico realizado por la UACH, habría que decir que en el supuesto concreto del caso CELCO sólo existe una fuente de emisión. En efecto, se investigó aguas arriba de la factoría y no se encontraron los componentes químicos que sí se encontraron aguas abajo sin que parezca que aguas abajo existiera otra fuente distinta. En consecuencia, se puede afirmar que la única fuente de emisión fue CELCO y, por tanto, la causante de los vertidos.

\subsubsection{La imputación objetiva del resultado.}

Una vez analizada la relación de causalidad y afirmada ésta procede investigar si el resultado es objetivamente imputable al sujeto o sujetos analizados.

Para afirmar la existencia de imputación objetiva la doctrina de forma general para todos los delitos ha establecido tres criterios que son excluyentes, es decir, que si no concurre el primero de ellos no tendremos que seguir investigando la concurrencia del resto:

\section{a) Creación de un riesgo no permitido o aumento del riesgo.}

Este primer criterio de la imputación objetiva significa que debemos analizar si la conducta llevada a cabo -propagación de sustancias- ha creado el riesgo de afectación al medio ambiente. En otros términos, si la realización de los vertidos de sustancias químicas suponen un riesgo para el medio ambiente. La respuesta, como no podía ser de otra forma, ha de ser afirmativa: cualquier vertido de sustancias químicas puede poner en peligro el medio ambiente. Ahora bien, recordemos que señalamos que en el ámbito del medio ambiente hay vertidos que están permitidos siempre que se adecúen a lo establecido en la normativa administrativa o en la lex artis. Estos vertidos, efectivamente, crean un riesgo para el medio ambiente pero es un riesgo permitido o utilizando la denominación que se emplea en el art. 291 del CP no son "indebidos". Por tanto, en el ámbito del medio ambiente a la hora de analizar la imputación objetiva no podemos acudir al criterio de creación de riesgo, sino al del incremento del riesgo. ¿Cuándo un vertido incrementa el riesgo de producir un resultado en el medio ambiente? De forma general, se puede decir que se ese incremento del riesgo se produce cuando el vertido se realiza de forma contraria a lo establecido en la normativa administrativa. Nótese que la normativa administrativa en

\footnotetext{
${ }^{43}$ Cuestión que hay que analizar posteriormente en fase de imputación objetiva.
} 


\section{Polit. crim. Vol. 5, No 10 (Diciembre 2010), Art. 4, pp. 410 - 454. [http://www.politicacriminal.cl/Vol_05/n_10/Vol5N10A4.pdf]}

este ámbito, como en otros muchos, es la que establece las fronteras entre el riesgo permitido y el que no lo está. Si se sobrepasan los límites de vertido establecido en la normativa administrativa o se vierten sustancias prohibidas por la normativa administrativa, entonces concurrirá este primer elemento de la imputación objetiva: incremento del riesgo. A nuestro entender, no existen dudas de que en el caso CELCO concurra este primer criterio: muchos de los vertidos realizados, conforme a lo establecido en el Informe de la $\mathrm{UACH}$, eran de sustancias no permitidas por la Resolución administrativa. En consecuencia, existe un claro incremento del riesgo.

\section{b) Concreción del riesgo en el resultado (de peligro).}

Fundamentalmente lo que se analiza en este segundo criterio de imputación objetiva es la probabilidad de que se produjese ese resultado tal y como se produjo. Dicho de otra forma, es necesario preguntarse si, ex ante, y conforme a los conocimientos del hombre medio más los especiales que pudiera tener el autor concreto-, era probable que llevando a cabo esa acción se produjese el resultado tal y como se produjo. Aplicado esto al ámbito del medio ambiente habría que decir que este criterio concurriría cuando -reiteramos, conforme a los conocimientos del hombre medio, más los especiales que pudiera tener el autor- el vertido de una determinada sustancia -que incrementa el riesgo permitido conforme al criterio anterior- es probable que ponga en peligro el medio ambiente. Si se observa, aquí la probabilidad no viene referida a si iban a producir una mayor o menor mortandad de especies o plantas sino al resultado requerido por el tipo del art. 291: peligro para la vida animal, vegetal o salud pública. Centrándonos en el supuesto del caso CELCO habría que afirmar la concurrencia del segundo criterio de la imputación objetiva: resulta altamente probable que si se realizan unos vertidos que están fuera de lo permitido por la normativa administrativa -incrementan el riesgo- se ponga en peligro el medio ambiente tal y como acaeció. En otros términos no existe ningún factor imprevisible entre la conducta llevada a cabo por el sujeto y el resultado final producido. Pero nótese, además, que este segundo criterio no requiere establecer la alta probabilidad de que desapareciera la planta luchecillo y que se produjese la mortandad de cisnes, sino única y exclusivamente, como exige el tipo del art. 291: la puesta en peligro de la salud animal, vegetal o pública. Dicho en otros términos, no es necesario afirmar la alta probabilidad científica de que las sustancias vertidas hiciesen que el hierro se depositase en las plantas, que estas muriesen o que fuesen ingeridas por los cisnes y estos muriesen, sino sólo si existía una alta probabilidad de que de forma genérica se pusiese en peligro el medio ambiente.

c) Que el resultado se encuentre dentro de los que quiere evitar la norma o dentro del fin de protección de la norma.

Pueden existir casos en que se cree o incremente un riesgo y que el resultado que era probable que se produjese se produzca pero, sin embargo, en los que no existe imputación objetiva. Se trata de supuestos que cumpliendo los dos primeros requisitos de la imputación objetiva no son de los que la norma pretende evitar porque se encuentran fuera de ámbito de previsión. En el supuesto del caso CELCO habría que preguntarse ¿el resultado de peligro para el medio ambiente es de los que pretende evitar el art. 291? La respuesta, a nuestro entender, es totalmente afirmativa; precisamente esos son los supuestos paradigmáticos que pretende evitar el tipo. 
MUÑOZ L., José; FERNÁNDEZ C., José Angel "Estudio dogmático penal de los artículos 291 del Código penal y 136 de la Ley General de Pesca y Acuicultura. A propósito del caso del Santuario de la Naturaleza Carlos Anwandter.

\subsubsection{El tipo omisivo: la comisión por omisión.}

Como ya se ha señalado con anterioridad el delito del art. 291 del CP es un delito resultativo, esto es, que requiere la presencia de un resultado de propagación $-\mathrm{y}$, también, como se verá, de peligro- pero que no exige que esa propagación haya que llevarse a cabo mediante una acción, sino que es posible que sea fruto de una omisión que queda equiparada a efectos de pena con la acción.

La estructura típica del tipo de comisión por omisión presenta, de acuerdo con la mayoría de la doctrina, una serie de peculiaridades generales. En cuanto la tipicidad objetiva requiere: a) una situación típica, que incluye una producción de un resultado previsto en el tipo; b) la ausencia de una acción esperada y obligada; c) la capacidad para realizar la acción y evitar el resultado; d) la concurrencia de una posición de garante; y e) una imputación objetiva del resultado. Por lo que respecta al tipo subjetivo, el dolo debe abarcar no sólo la ausencia de la acción debida, sino su posición de garante, el resultado y el juicio de imputación objetiva.

De esta manera, el tipo de comisión por omisión del art. 291 CP requiere una propagación indebida -resultado-; la ausencia de una acción esperada que resulta exigible por la posición de garante del sujeto que le obligaba a realizar dicha acción; la capacidad para realizar dicha acción y evitar el resultado; y un conocimiento y voluntad de la ausencia de la acción, de la posición de garante, del resultado, el juicio hipotético de imputación objetiva y el peligro para los bienes jurídicos protegidos. Respecto del tipo subjetivo, el dolo, debemos recalcar que no requiere el conocimiento de la efectiva lesión a estos bienes (por ejemplo, la desaparición del lucecillo y la mortandad de los cines de cuello negro), sino exclusivamente la propagación indebida y del peligro para la salud pública, animal o vegetal.

\section{a) Especial referencia a la posición de garante.}

La doctrina mayoritaria y la jurisprudencia establecen como principal elemento típico de la comisión por omisión la concurrencia de la posición de garante. La posición de garante en la comisión por omisión es el vínculo que sirve para equipar la omisión a la acción descrita en el tipo penal.

Concurre la situación de garante cuando corresponde al sujeto una específica función de protección del bien jurídico afectado o una función personal de control de una fuente de peligro. En ambos casos, el autor es garante de la indemnidad del bien jurídico.

La teoría de las funciones de Kaufmann asienta la posición de garante en una relación materialmente existente entre el sujeto y el bien jurídico. Se supera así, la anterior doctrina de la teoría formal del deber jurídico, que para decidir la existencia de una posición de garante atendía a sus fuentes formales (ley, contrato y actuar precedente). No basta con el incumplimiento de cualquier deber para imputar un resultado (padres que no alimentan a un 
hijo menor pero que puede valerse por sí mismo), sino que debe existir una equivalencia entre la omisión y la acción descrita en el tipo. ${ }^{44}$

Gracia Martín, y otros, han criticado la anterior posición. La principal crítica reside que, al exigirse la posición de garante, se incluye un nuevo elemento típico que no concurre en el tipo de acción descrito expresamente, y por tanto, se vulnera el principio de legalidad, además de que, en algunos casos, la posición de garante no fundamenta una mayor intensidad penal. Estos autores mantienen que la equiparación entre el tipo de acción dolosa expresamente tipificada y el tipo de comisión por omisión debe ser axiológica, con independencia de la posición de garante. Así, el tipo de homicidio doloso requiere que una persona mate a otra, pero no necesariamente de manera causal. En todo caso, la posición de garante constituye para esta doctrina un indicio valorativo. ${ }^{45}$

La relación material puede proceder del deber de protección del bien jurídico protegido o del deber de control de una fuente de peligro. En todo caso en la mayoría de supuestos concretos concurren ambas relaciones materiales.

Los supuestos más frecuentes donde puede aparecer una posición de garante en el ámbito de las organizaciones complejas son las siguientes:

- El deber de control de fuentes de peligro que operan en el propio ámbito del dominio. Quien posee en su esfera de dominio una fuente de peligro (máquinas, instalaciones etc.) es el responsable de que tal peligro no se realice.

- Responsabilidad por la conducta de otras personas. En determinadas condiciones, ciertas personas tienen el deber de vigilar a otras. En estos supuestos deben tenerse presente los principios de confianza y de división del trabajo a la hora de delimitar la responsabilidad penal de ambos intervinientes (vigilado y vigilante). ${ }^{46}$

\section{b) El juicio hipotético en los delitos de comisión por omisión.}

El resultado sobre el que se funda el tipo de comisión por omisión requiere de una relación entre la conducta y el resultado, relación que, conforme al principio de legalidad, no puede ser obviado aunque, de acuerdo con la doctrina mayoritaria, puede ser sustituido con un juicio hipotético. En un sentido científico-natural la omisión no causa nada, porque se caracteriza por la ausencia de energía: et nihilo nihil fit. ${ }^{47}$ En otros términos, una omisión nunca inicia un curso causal que desemboque en un resultado, sino que la omisión no detiene un curso causal que se ha iniciado por otros factores.

\footnotetext{
${ }^{44}$ KAUFMANN, Armin, Dogmática de los delitos de omisión, Madrid: Marcial Pons, 2006.

45 GRACIA MARTÍN, Luis, "Los delitos de comisión por omisión. (Una exposición crítica de la doctrina dominante)", en: Modernas tendencias de la Ciencia del Derecho penal y en la Criminología, Madrid: Universidad Nacional de Educación a Distancia, 2000, pp. 411-482.

${ }^{46}$ Respecto de los principios de confianza y división del trabajo, véase, supra, III.2.1.1.

47 GIMBERNAT ORDEIG, Enrique, La causalidad en la omisión impropia y la llamada "omisión por omisión”, Buenos Aires: Rubinzal-Culzoni, 2003, p.20.
} 
MUÑOZ L., José; FERNÁNDEZ C., José Angel “Estudio dogmático penal de los artículos 291 del Código penal y 136 de la Ley General de Pesca y Acuicultura. A propósito del caso del Santuario de la Naturaleza Carlos Anwandter.

La doctrina mayoritaria realiza esta conversión típica a través de la siguiente regla de imputación: "cuando la acción debida hubiera evitado el resultado con una probabilidad rayana en la seguridad o certeza, la omisión habrá causado el resultado." No obstante, esta doctrina ha sido objeto de varias críticas.

La primera de ellas, radica en las dificultades probatorias que supone la convicción de que una omisión pudo evitar rayando la certeza un determinado resultado; en otros términos, se intentaría probar algo que no ha ocurrido. A mayor abundamiento, en los tipos de comisión por omisión se requiere, en principio, establecer dos relaciones de causalidad: la causa o causas directas que originaron el resultado y el juicio hipotético de que una determinada acción hubiera evitado este resultado. Ahora bien, debemos plantearnos si en todos los casos es necesario determinar la causa del resultado y, en especial, cuando la fuente de peligro depende el garante. Por ejemplo, si previamente, se tiene conciencia de que cierto resultado puede proceder de varias fuentes de peligro (curso causal complejo) y de la dificultad que conlleva su determinación causal y, por ese motivo, se establece una especial posición de garante sobre este peligro, a nuestro entender, sólo será necesario probar el resultado (la contaminación) y el juicio hipotético. No obstante, si retomamos los nuevos cuestionamientos doctrinales sobre la relación de causalidad activa mencionados con anterioridad, podemos advertir que, al menos, en los casos de contaminación, el juicio hipotético presenta las mismas dificultades probatorias. En los casos más complejos, como es el caso de la contaminación, tanto la relación de causalidad como el juicio hipotético, presenta problemas probatorios, que como hemos mencionado, parte de la doctrina resuelve a través de juicio de probabilidad. Es decir, no existe la seguridad científica, desde una concepción clásica del positivismo científico, de que tanto la acción realizada como la acción omitida hubieran evitado el resultado. Todo lo anterior, sin perjuicio, de reconocer que ontológicamente la relación causal entre la omisión y el resultado es hipotético y, por tanto, al no ser real sólo se puede predicar una más o menos elevada probabilidad, pero nunca la seguridad de que hubiera evitado el resultado. Por esta razón, el juicio hipotético estructurado como un juicio de probabilidad, sufre la misma crítica que la concepción de la causalidad también concebido en términos probabilísticos: la transformación de los delitos de lesión en delitos de peligro. ${ }^{48}$

3.1.7. La puesta en peligro de la salud pública, animal y vegetal. El peligro hipotético.

El último elemento recogido en el tipo del art. 291 del CP y, sin el cual, el delito no puede estar definitivamente consumado, es la puesta en peligro de la salud pública, animal o vegetal.

La propagación indebida constituye una condición necesaria pero no suficiente. El principio de lesividad se manifiesta en el art. $291 \mathrm{CP}$ con el requisito de la puesta en peligro de determinados bienes jurídicos (salud pública, animal y vegetal). De este modo, el desvalor estrictamente penal es precisamente la puesta en peligro, además, de constituir a priori el elemento diferenciador con el derecho sancionador administrativo.

\footnotetext{
${ }^{48}$ En el caso de los tipos de comisión por omisión, GIMBERNAT, La causalidad en la omisión impropia, cit. nota $\mathrm{n}^{\circ} 47$, p. 45
} 
El art. 291 del CP expresamente requiere que las propagaciones indebidas sean susceptibles de poner en peligro la salud animal o vegetal, o la salud pública. Es decir, cuando se exige que una determinada acción $\mathrm{u}$ omisión sean susceptibles de poner en peligro un bien jurídico protegido, quiere decir que no es preciso que en el caso concreto se cree un peligro efectivo similar al que, por ejemplo, debe concurrir en la tentativa. Esta falta de concreción del peligro no significa que estemos ante un delito de peligro presunto, en el sentido de que no se exija ningún efectivo peligro; si fuese un delito de peligro presunto, para la consumación del tipo bastaría con la realización de los vertidos de manera "indebida", esto es contraria a la normativa administrativa porque, en ese caso, el legislador considera que la acción es generalmente peligrosa y no cabe prueba en contrario.

Tampoco se trata de un tipo que requiera como resultado de la conducta la proximidad de una concreta lesión (delitos de peligro concreto), sino la peligrosidad de la conducta, peligrosidad que se supone inherente a la acción, salvo que se pruebe que el caso concreto quedó excluida de antemano. ${ }^{49}$

En realidad, el art. $291 \mathrm{CP}$ es un tipo de peligro hipotético, también denominados por otros sectores doctrinales como delitos de "peligro posible", de "aptitud", de "idoneidad", de "peligro concreto ex ante", de "peligro abstracto con idoneidad lesiva objetiva" o "de idoneidad concreta ex ante". ${ }^{50}$ Evidentemente, con independencia de la denominación que se le quiera dar, a lo que hay que atender es a la materialidad de todos esos conceptos o, si se quiere, a la forma de constatar la presencia del peligro que, a nuestro juicio, en todos ellos es idéntica. No obstante, aquí se opta por utilizar la denominación de "peligro hipotético" porque, a nuestro entender, es la más comúnmente utilizada en la doctrina desde que la propusiese Torío López- ${ }^{51}$

Cualquiera que sea su denominación, lo cierto es que los delitos de peligro hipotético se encuentran a medio camino entre los delitos de peligro abstracto y los delitos de peligro concreto. Los delitos de peligro hipotético tienen la virtualidad de facilitar las laboriosas y enrevesadas cuestiones de prueba en relación con el peligro y, por otro lado, también tienen la ventaja de evitar la confusión entre las infracciones penales y las administrativas.

Los delitos de peligro hipotético, como se ha señalado, presentan una estructura intermedia entre los delitos de peligro concreto y los de peligro abstracto o presunto; sin embargo, a efectos sistemáticos, resulta conveniente encuadrarlos dentro de estos últimos. Si se quiere, los delitos de peligro hipotético serían una subcategoría de los delitos de peligro abstracto

\footnotetext{
${ }^{49}$ Por todos, MIR PUIG, Derecho penal, cit. nota $n^{\circ} 30$, p. 228. Incluso, en el caso del inciso primero del art. $325 \mathrm{CP}$ español -que exige que las conductas y resultados descritos puedan perjudicar gravemente el medio ambiente, y por tanto una concreción más intensa de la afección del bien jurídico- una parte importante de la doctrina entiende que estamos ante un delito de peligro abstracto en el sentido de una idoneidad concreta ex ante. SILVA SÁNCHEZ, Delitos contra el medio ambiente, cit. nota $\mathrm{n}^{\circ} 28, \mathrm{p} .76$.

${ }^{50} \mathrm{Al}$ respecto, y en mayor extensión, véase MUÑOZ LORENTE, José, "Algunas consideraciones sobre los delitos contra el medio ambiente en la jurisprudencia del Tribunal Supremo”, Revista del Poder Judicial, $\mathrm{N}^{\circ}$ 67 (2002), pp. 167 y ss.

${ }^{51}$ TORÍO LÓPEZ, A., "Los delitos de peligro hipotético (Contribución al estudio diferencial de los delitos de peligro abstracto)", $A D C P C P \mathrm{~N}^{\circ} 3$ (1981), pp. 825 y ss.
} 
MUÑOZ L., José; FERNÁNDEZ C., José Angel "Estudio dogmático penal de los artículos 291 del Código penal y 136 de la Ley General de Pesca y Acuicultura. A propósito del caso del Santuario de la Naturaleza Carlos Anwandter.

en sentido amplio que, a su vez, se dividirían entre delitos de peligro abstracto en sentido estricto o peligro presunto, y delitos de peligro hipotético.

Los delitos de peligro hipotético se encuadran en la categoría de los delitos de peligro abstracto en sentido amplio porque, a diferencia de los delitos de peligro concreto, no exigen la producción de un peligro efectivo y concreto separado espacio-temporalmente de la acción del sujeto, esto es, que vaya más allá de la acción o conducta típica; es decir, no resulta necesario probar que el objeto de la acción -el medio ambiente- se ha encontrado en el radio de acción de la conducta y que respecto a ese objeto se ha producido un peligro real de lesión, es decir, realmente se ha estado a punto de causar una lesión que, por suerte, no ha acaecido. En otros términos, a diferencia de los delitos de peligro concreto, en los delitos de peligro hipotético no es necesario probar la existencia de un peligro efectivo y real o próximo para el objeto de la acción producido ex post a dicha acción.

Pero, de la misma forma, en el caso de los delitos de peligro hipotético, y a diferencia de los delitos de peligro abstracto en sentido estricto, no basta simplemente con contravenir la normativa administrativa sobre la materia y entender que iuris et de iure concurre el peligro. Es decir, el tipo de peligro hipotético no describe acciones que con carácter general, y por el mero hecho de contravenir la normativa administrativa per se presumen peligrosas y, por eso, se aplica el tipo, sino que además es necesario que dicha acción sea generalmente apta o idónea para poner en peligro el bien jurídico en el caso concreto.

Como resulta comprensible que esas definiciones, en sí mismas son muy abstractas y que la ciencia jurídica, a mi entender, ha de partir de la base de que el Derecho es una materia viva - esto es, que se aplica diariamente por los Tribunales- conviene analizar la cuestión en referencia a ejemplos concretos.

Pongamos un ejemplo en relación con unos vertidos. Imaginemos un río altamente contaminado cuya fauna piscícola desapareció hace varios años por efecto de la cantidad de vertidos realizados durante años. Pues bien, cuando ya ha desaparecido toda la fauna y la vegetación de las riberas, pensemos que se realiza un vertido que contraviene la normativa administrativa ¿Se podría decir que en este caso concurre peligro concreto para el medio ambiente o para el ecosistema cuando, como se ha señalado, ese ecosistema ha desaparecido por el efecto de todos los vertidos que con anterioridad han realizado otras empresas? Habría que contestar negativamente a la cuestión. En efecto, es imposible probar que se ha puesto en peligro concreto un ecosistema que, por el efecto de vertidos anteriores, ya no existe $\mathrm{o}$, si se quiere, no se puede poner en peligro de lesión -concreta y real- un ecosistema que ha desaparecido completamente; en consecuencia, habría que declarar impune la conducta de entender que el tipo es un tipo de peligro concreto. Sin embargo, si lo conceptuamos como un delito de peligro hipotético no habría ningún problema para considerar que esa conducta se encuadra en el tipo porque, si bien, la misma no crea ningún peligro concreto de lesión - puesto que la lesión ya se ha producido con anterioridad, el ecosistema ha desaparecido- sí resulta generalmente apta o idónea para crearlo en un ecosistema similar y no contaminado por el efecto de vertidos realizados durante años. Es decir, lo esencial en el peligro hipotético es analizar si esa concreta conducta 
potencialmente resultaba apta para haber lesionado ese ecosistema o cualquier otro similar que hubiese estado en perfectas condiciones. Esto es, precisamente, el peligro hipotético.

Pongamos otro ejemplo. Supongamos que se realizan unos vertidos a un río contraviniendo la normativa administrativa. Nada más realizarse los vertidos, por pura suerte, empieza a llover y aumenta enormemente el caudal del río hasta el punto de que los vertidos, debido a ese gran caudal no habitual se disuelven totalmente en el agua. De interpretar el tipo como de peligro concreto, este supuesto resultaría impune puesto que no crea un peligro real para el medio ambiente. Para que ese supuesto resultase punible sería necesario interpretarlo como un tipo de peligro hipotético y preguntarse: ¿de no haber llovido en ese justo momento habría puesto en peligro el medio ambiente? La contestación ha de ser afirmativa.

En relación con los hechos acaecidos en el Santuario Carlos Anwandter, sólo hay que exigir la prueba de la existencia del peligro hipotético y no el peligro en concreto, y menos la efectiva lesión de la salud animal, vegetal o pública que, aunque se ha producido, no la exige el tipo. Ahora bien, en el caso del Santuario Carlos Anwandter, los diferentes estudios científicos que expliquen la relación causal entre determinadas actividades y lo acaecido en el citado Santuario, podrá tener incidencia en los siguientes aspectos: como una prueba indiciaria del juicio de imputación de la peligrosidad de la conducta, como fundamento de una mayor extensión del mal causado (art. $69 \mathrm{CP}$ ) y como prueba, ahora sí, de la relación de causalidad de otras figuras penales como lesiones (dolosas o imprudente), daños, etc., que entrarían en concurso con el delito del art. $291 \mathrm{CP}$.

En cuanto a la intensidad del peligro, si tenemos presente que la salud animal, vegetal y pública está protegida a la vez por el derecho sancionador, podemos concluir que el art. 291 $\mathrm{CP}$ requiere la concurrencia de un peligro grave. A pesar de no estar descrito expresamente -como en el caso del art. 325. 1 CP español- el principio de lesividad y la ratio legis del precepto nos deriva a esta conclusión. La doctrina ha establecido los siguientes requisitos para evaluar la gravedad del peligro: a) la mayor o menor probabilidad de lesión; y b) la magnitud de la lesión previsible en función de la extensión en el espacio, la prolongación en el tiempo y la intensidad de la afección o incidencia. ${ }^{52}$ Los delitos de peligro abstracto que la doctrina denomina de aptitud o idoneidad, exigen que la conducta tenga una idoneidad para producir un daño que se constate que supera ciertos niveles de permisión de riesgos y esta exigencia de idoneidad deja más clara la diferenciación entre el injusto específicamente penal y el administrativo. ${ }^{53}$

Una de las cuestiones más interesantes, como son los casos en los que los perjuicios a las aguas se producen en forma cumulativa, es decir, que las aguas se contaminen en etapas, y que con la suma de cada una de ellas se consiga la misma intensidad perjudicial. Si acudimos al concepto de unidad jurídica de la acción o del supuesto de hecho fáctico, podemos concluir que un perjuicio a las aguas causado de esta manera cumulativa cumple el tipo del art. 291 CP. No obstante, esta forma especial forma de producción debe cumplir con las exigencias de causalidad y de imputación objetiva.

\footnotetext{
${ }_{52}^{52}$ Por todos, SILVA SÁNCHEZ, Delitos contra el medio ambiente, cit. nota ${ }^{\circ} 28, \mathrm{p} .79$.

53 FEIJOO SÁNCHEZ, Bernardo, Normativización del Derecho penal y realidad social, Bogotá: Ed. Universidad Externado de Colombia, 2007, pp. 318-320.
} 
MUÑOZ L., José; FERNÁNDEZ C., José Angel "Estudio dogmático penal de los artículos 291 del Código penal y 136 de la Ley General de Pesca y Acuicultura. A propósito del caso del Santuario de la Naturaleza Carlos Anwandter.

\subsubsection{Autoría y participación.}

El tipo se estructura como un delito común, y por tanto, no resultan necesarios especiales elementos o condiciones en la autoría. No obstante, en el presente estudio resulta interesante profundizar en los criterios de imputación del dominio del hecho sobre sujetos que normalmente no serán quienes de modo directo hayan realizado la última aportación causal al hecho (normalmente subalternos). Así, resulta de especial interés la imputación por autoría mediata y la imputación de la autoría en el seno de estructuras empresariales especialmente complejas. ${ }^{54}$

\section{a) La autoría mediata.}

Autor mediato es el que realiza el tipo, aunque no lo ejecuta directamente, sino que para esta ejecución se sirve de otra persona que actúa como instrumento de su voluntad. El término "instrumento de su voluntad" hay que entenderlo en sentido estricto, es decir, que la ejecución directa aparezca como obra del hombre de atrás o autor mediato. Aquí reside la diferencia fundamental entre autoría mediata e inducción. En los delitos comunes dolosos sólo puede ser "instrumento", por tanto, quien en sí mismo no es un autor plenamente responsable (con la salvedad específica, para parte de la doctrina, de quien actúa como instrumento ejecutor en el seno de los aparatos organizados del poder). Como consecuencia de ese domino de la voluntad el autor mediato realiza el tipo, aunque no la ejecución directa-material del mismo. Salvo la excepción señalada, esto implica que el instrumento quede impune, porque no puede imputársele a él la realización del tipo, ni tampoco puede afirmarse su participación en él. ${ }^{55}$

La autoría mediata exige acreditar la efectiva instrumentalización del subordinado mediante órdenes o indicaciones que den lugar a la producción del hecho.

Dentro de los supuestos de autoría mediata en los delitos comunes dolosos, resultan de especial aplicación en el ámbito de la contaminación los de error en el instrumento, y en especial, sobre el carácter indebido de la actividad contaminante. La doctrina ha determinado los siguientes grupos de casos:

- Quien crea un error sobre el tipo en otra persona, o utiliza delictivamente el estado de error de otro, es autor mediato del delito doloso, ya que el instrumento actúa sin dolo.

- Si el ejecutor directo actuase imprudentemente, porque podía haber previsto tal acontecer, la conducta del hombre de atrás es de autoría mediata del delito doloso, y la del ejecutor es de autoría directa accesoria del delito imprudente.

\footnotetext{
${ }^{54}$ Con la reciente promulgación de la Ley No 20.393 que establece la Responsabilidad Penal de las Personas Jurídicas en los Delitos de Lavado de Activos, Financiamiento del Terrorismo y Delitos de Cohecho, aunque como su proprio título indica, no abarca los delitos in comento, puede ser el precedente para que en el futuro pueda ampliarse este tipo de responsabilidad a la delincuencia cometida en el seno de las grandes organizaciones empresariales, sin perjuicio, que en algunos supuestos se les pueda aplicar esta ley cuando el delito subyacente sea el de lavado de dinero.

${ }^{55}$ Por todos, GÓMEZ BENÍTEZ, Teoría jurídica del delito, cit. nota n ${ }^{\circ} 38$, p. 151.
} 


\section{Polit. crim. Vol. 5, No 10 (Diciembre 2010), Art. 4, pp. 410 - 454. \\ [http://www.politicacriminal.cl/Vol_05/n_10/Vol5N10A4.pdf]}

- Si el "hombre de atrás" creó o aprovechó un estado de error invencible sobre la prohibición del instrumento, suele reconocerse la autoría mediata de aquél, y la irresponsabilidad penal del instrumento, que actuó dolosamente, pero sin culpabilidad. ${ }^{56}$

Obsérvese que en este último supuesto, a diferencia de los casos de error sobre el tipo, aquí se afirma la concurrencia de dolo en el instrumento, aunque no la culpabilidad. Son casos en que el autor mediato utiliza un instrumento doloso, pero no culpable, por lo que también podrían sustanciarse, teóricamente, como supuestos de inducción. De nuevo debe decidirse aquí -al igual que en los casos de utilización de inimputables- a favor de la autoría mediata, ya que el error invencible del instrumento ejecutor directo concede siempre el domino de la voluntad al hombre de atrás, que no sólo hace nacer la voluntad delictiva en el ejecutor directo -lo que lo mantendría en la calificación de partícipe inductor- sino que domina el hecho dominando la voluntad del ejecutor directo.

Las dudas se plantean en los supuestos de error vencible de prohibición del instrumento ejecutor. En estos casos el instrumento ejecutor no sólo realiza el tipo doloso y antijurídico, sino que actúa, además con culpabilidad, aunque disminuida. Esta concurrencia de todos los elementos del delito en la acción del instrumento ha movido a la doctrina dominante a considerar que estos casos no concurre la autoría mediata el que creó o aprovechó ese error evitable del ejecutor directo del hecho. Por eso se considera que el domina el hecho es, en este caso, precisamente, el ejecutor directo, y no el hombre de atrás, del que no puede decirse que el hecho aparezca como obra suya, es decir, como obra de su voluntad. El hombre de atrás sólo aparece aquí como partícipe inductor si creó el estado de error evitable, o como partícipe cómplice si sólo se aprovechó del mismo. ${ }^{57}$

b) Imputación de hechos delictivos en estructuras empresariales complejas. ${ }^{58}$

La sociedad actual se identifica por una nueva forma de organización: las estructuras empresariales complejas. El derecho penal se caracteriza por imputar el delito y la correspondiente pena a las personas físicas (trabajadores, administradores, directivos, etc.), es decir, como conductas realizadas individualmente donde el autor realiza y conoce de manera completa el contenido del delito. De esta manera, la dogmática tradicional y la praxis judicial no han tenido presente la compleja estructura de ciertas organizaciones, que viene siendo tratada por la denominada sociología de la organización. Así, se ha puesto de relieve que, por ejemplo, ciertas empresas no pueden ser tratadas como una suma de sujetos individuales, sino que suponen una nueva realidad social distinta a la de aquéllos. En estas estructuras organizativas ya no encontramos a un autor que ejecute un hecho típico con conocimiento del alcance de su decisión, sino que, por el contrario, no resulta posible encontrar, o al menos, resulta extremadamente difícil, una persona en el entramado empresarial en la que coincidan la creación del riesgo y participación en el mismo con la correspondiente relación subjetiva (dolo o imprudencia), sino que por el contrario,

\footnotetext{
${ }^{56}$ GÓMEZ BENÍTEZ, Teoría jurídica del delito, cit. nota ${ }^{\circ}$ 38, p. 489.

${ }^{57}$ GÓMEZ BENÍTEZ, Teoría jurídica del delito, cit. nota ${ }^{\circ}$ 38, p. 490.

58 Este epígrafe toma como referencia la investigación realizada por FEIJOO SÁNCHEZ, Bernardo, "Imputación de hechos delictivos en estructuras empresariales complejas", en: Centro de Investigación Interdisciplinaria en Derecho Penal Económico, 2009, pp. 1-30.
} 
MUÑOZ L., José; FERNÁNDEZ C., José Angel "Estudio dogmático penal de los artículos 291 del Código penal y 136 de la Ley General de Pesca y Acuicultura. A propósito del caso del Santuario de la Naturaleza Carlos Anwandter.

participan varias personas sin que en ninguna de ellas coincida plenamente la parte objetiva y subjetiva del tipo penal. Esta nueva realidad criminal tiene como causa el hecho de que en estas complejas organizaciones nadie, incluso, los propios directivos, poseen un visión global que les permita entender la peligrosidad que encierran determinadas actividades industriales o empresariales. A mayor abundamiento, en la gran empresa no suele concurrir en las mismas personas la información, conocimientos técnicos, capacidad para tomar decisiones y ejecución de éstas. ${ }^{59}$ Así, la doctrina ha denominado como "irresponsabilidad penal organizada" aquellos supuestos donde la responsabilidad penal no corresponde a una conducta o conductas individuales, sino a las deficiencias en la estructura empresarial. ${ }^{60}$ Como manifiesta Feijoo Sánchez esta situación no se debe principalmente a una creación intencionada o fraudulenta de irresponsabilidad, sino más bien como problema estructural de esto tipo de organizaciones. ${ }^{61}$

La necesidad de una adecuada respuesta jurídico penal ante estas nuevas relaciones sociales resulta también necesaria para evitar la también estructural tendencia de aplicar el Derecho Penal a las clases más vulnerables, es decir, en el caso que nos ocupa, a los últimos eslabones de cadena empresarial, que normalmente, ejecutarán la conducta que lesionará o pondrá en peligro el bien jurídico protegido. Ahora bien, tampoco se pretende castigar a los directivos, gerentes o dueños de la empresa por el solo hecho de ostentar un deber general de vigilancia sobre todos sus trabajadores. Incluso, desde una posición socialdemócrata de la política criminal que plantee una incorporación de las clases poderosas al Derecho Penal, no resultan aceptables manifestaciones del denominado bienestarismo penal autoritario, que en último término podría derivar en una responsabilidad penal objetiva. Por el contrario, debe partirse de una adecuada legislación penal, una desarrollada dogmática penal, una adecuada formación especializada de los operadores policiales y jurídicos para cumplir, dentro de la estructural naturaleza discriminatoria del derecho penal, las exigencias derivadas del contrato social.

Una respuesta ante este nuevo desafío dogmático ha consistido en aplicar los criterios de imputación de la teoría del dominio del hecho mediante aparatos organizados del poder, a partir de la pionera contribución de Schünemann en $1979 .{ }^{62}$ Feijoo Sánchez manifiesta que, más allá de las críticas que ha recibido el tratamiento de los aparatos organizados del poder por la teoría del dominio del hecho, resulta evidente que Roxin no construyó esta categoría dogmática para resolver los problemas que presentan las estructuras empresariales complejas, sino para los delitos de Estado o grandes organizaciones criminales. ${ }^{63}$ En estos

\footnotetext{
${ }^{59}$ FEIJOO SÁNCHEZ, "Imputación de hechos delictivos”, cit. nota ${ }^{\circ} 58$, pp. 1 - 5.

${ }^{60}$ Por todos, FEIJOO SÁNCHEZ, "Imputación de hechos delictivos", cit. nota ${ }^{\circ}$ 58, p. 6. A este concepto le añadiría el adjetivo de "fáctica" para recalcar que la irresponsabilidad se debe más a cuestiones de hecho que jurídicas.

${ }^{61}$ FEIJOO SÁNCHEZ, "Imputación de hechos delictivos", cit. nota n 58, p. 6.

${ }^{62}$ SCHÜNEMANN, Bernd, Unternemhencriminalität und Strafrecht, Berlin, 1979.

${ }^{63}$ FEIJOO SÁNCHEZ, "Imputación de hechos delictivos", cit. nota n 58, p. 12. Además como manifiesta el autor citado, el propio Roxin se muestra en contra de esta posición. ROXIN, Claus, Autoría y Participación, Madrid: Marcial Pons, 1998, p. 729; BACIGALUPO, Silvina, Autoría y Participación en los delitos de infracción de deber. Una investigación aplicable al Derecho penal de los negocios, Madrid: Marcial Pons, 2007, pp. 121-138.
} 


\section{Polit. crim. Vol. 5, No 10 (Diciembre 2010), Art. 4, pp. 410 - 454. \\ [http://www.politicacriminal.cl/Vol_05/n_10/Vol5N10A4.pdf]}

casos, no estaríamos ante un "dominio fáctico del hecho concreto", como sucede en los crimines contra la humanidad cometidos por el Estado, sino ante un "domino sobre la organización". ${ }^{64}$ El propio Roxin resuelve la imputación del dominio de la organización a través de los denominados delitos de infracción del deber, obligación que consistiría en una suerte de posición de garante de la legalidad. Pero esto significaría, de acuerdo con Feijoo, a una renuncia a la idea rectora del domino del hecho, ${ }^{65}$ es decir, a la imputación material en los delitos comunes.

Finalmente, Feijoo Sánchez acude a los principios de confianza y división del trabajo para delimitar las esferas de responsabilidad dentro de las organizaciones empresariales complejas, posición que no debe resultar extraña ya que el autor constituye un referente dogmático en los delitos imprudentes, y ha sido en el seno de éstos donde se han desarrollado estos principios.

La aplicación de estos principios destinados a transmitir el riesgo entre los miembros de la organización plantea algunos supuestos problemáticos:

- Las relaciones entre los grupos de empresas. Aquí deberá establecerse, además de la relación normativa, si efectivamente se ha transmitido el riesgo entre ellas o, como manifiesta, Feijoo Sánchez si se conserva una posición de garante, normalmente, entre la empresa matriz y las subsidiarias.

- Los organigramas internos de la empresa, sólo poseen una función indiciaria para determinar el domino del hecho dentro de la organización, ${ }^{66}$ es decir, debemos evitar acudir a criterios formales como sucedió en las primeras formulaciones dogmáticas sobre la posición de garante en los delitos de comisión por omisión.

- Se debe determinar los ámbitos, secciones, departamentos, etc. que ostentan ámbitos funcionales independientes o autónomos. ${ }^{67}$ Esto significa que la investigación policial e instrucción penal deberán ir acotando el espacio empresarial donde supuestamente se ha cometido el injusto penal.

- El deber general de comunicación y coordinación del Consejo de Administración. Aquí se puede dar tanto un peligro de organización como un peligro de desorganización que pueden fundamentar una responsabilidad penal. Resultará de especial importancia la implementación, además de la legislación y reglamentación, de códigos de buenas prácticas, sistemas de análisis de riesgos, etc.

- Consejos de Administración en delitos de comisión por omisión imprudente. En estos casos es donde se puede plantear mayores problemas dogmáticos y probatorios a la

\footnotetext{
${ }^{64}$ Véase la doctrina citada por FEIJOO SÁNCHEZ, "Imputación de hechos delictivos", cit. nota n ${ }^{\circ} 58$, p. 14 (nota 21).

${ }^{65}$ FEIJOO SÁNCHEZ, "Imputación de hechos delictivos", cit. nota n ${ }^{\circ} 58$, p. 15 . Véase la doctrina citada por el autor.

${ }^{66}$ FEIJOO SÁNCHEZ, "Imputación de hechos delictivos", cit. nota n ${ }^{\circ} 58$, p. 22

${ }^{67}$ FEIJOO SÁNCHEZ, "Imputación de hechos delictivos”, cit. nota n 58, p.24.
} 
MUÑOZ L., José; FERNÁNDEZ C., José Angel "Estudio dogmático penal de los artículos 291 del Código penal y 136 de la Ley General de Pesca y Acuicultura. A propósito del caso del Santuario de la Naturaleza Carlos Anwandter.

hora de imputar el injusto penal a uno o varios del máximo órgano ejecutivo de la empresa. A fin de asegurar la adecuada transmisión del riesgo en aquellos casos especialmente graves, como por ejemplo, grandes empresas potencialmente contaminantes, existe una tendencia en el orden internacional de incluir en los consejos de administración miembros especializado en el control y supervisión de estos riesgos. ${ }^{68}$

\subsubsection{Iter criminis.}

El art. 291 CP se consuma con la constatación de la puesta en peligro de la salud pública, animal o vegetal. Además, el precepto está estructurado como un delito permanente lo que significa que la consumación se mantiene en el tiempo, bien porque continúa produciéndose las conductas de propagación, bien porque cesada la actividad el peligro no ha desaparecido. Esta naturaleza de delito de permanente afecta al plazo de prescripción y a la participación del delito. ${ }^{69}$

\section{Tipicidad subjetiva.}

$\mathrm{El}$ art. $291 \mathrm{CP}$ es un delito doloso, a tenor de nuestro sistema de incriminación de numerus clausus (imperfecto) de la imprudencia. Ahora bien, en el caso de que la propagación ponga en peligro la salud de las personas, cabe entender que estamos ante un delito contra las personas, y por tanto, desde una interpretación material de nuestro Derecho penal, podrían encuadrarse dentro del ámbito de aplicación del art. 490 y ss. CP. No obstante, la práctica totalidad de la doctrina acude a una interpretación gramatical y sistemática y considera que el ámbito de aplicación de los cuasidelitos se circunscribe a los delitos comprendidos en el Título VIII del Libro II del CP.

La exigencia de una tipicidad dolosa conlleva que no pueda ser interpretado como un tipo que incorpore una combinación de dolo respecto a la propagación e imprudencia en cuanto al peligro del bien jurídico. En sentido contrario, el dolo deberá abarcar todos los elementos típicos, y en especial, la puesta en peligro, pero en ningún caso los eventuales efectivas lesiones, como la desaparición del lucecillo o la muerte y migración de determinadas especies animales del Santuario. Así, el sujeto debe conocer y querer que una determinada conducta pueda producir una propagación y una puesta en peligro los bienes jurídicos protegidos. En todo caso, resulta suficiente la imputación a título de dolo eventual.

\subsection{Especial referencia al dolo eventual.}

La línea divisoria entre el tipo doloso y el tipo imprudente, si bien desde una perspectiva teórica ofrece una multitud de soluciones, en la práctica judicial constituye una de las situaciones donde se manifiesta una mayor inseguridad jurídica. Esta problemática se agudiza en los delitos ambientales, ya que normalmente en la determinación de la tipicidad

\footnotetext{
${ }^{68}$ FEIJOO SÁNCHEZ, "Imputación de hechos delictivos", cit. nota n ${ }^{\circ} 58$, p. 25.

${ }^{69}$ SILVA SÁNCHEZ, Delitos contra el medio ambiente, cit. nota $n^{\circ} 28$, p. 56 . Véase jurisprudencia española citada por el autor.
} 


\section{Polit. crim. Vol. 5, № 10 (Diciembre 2010), Art. 4, pp. 410 - 454. [http://www.politicacriminal.cl/Vol_05/n_10/Vol5N10A4.pdf]}

subjetiva tiene como referente una conducta que ha operado en el ámbito de un riesgo permitido.

Sin que podamos profundizar en esta prolija polémica doctrinal y en sus numerosas propuestas, habría que señalar que siendo los límites entre dolo e imprudencia tan indeterminados, es difícil reprocharle a cualquier teoría que no respeta los límites del dolo e invade el ámbito de la imprudencia, o viceversa. ${ }^{70}$ De los estudios que se han realizado con profundidad, todos coinciden que las fronteras entre dolo e imprudencia son más difusas que lo que puede aparentar un mero acercamiento superficial a esta cuestión. Ello es debido en gran medida a que cuando un dogmático intenta determinar los límites del conocimiento se muestra inseguro, ya que se trata de un tema perteneciente a disciplinas que no domina como la psicología, la psiquiatría, la filosofía del lenguaje o la medicina. Se trata además, como hemos afirmado, de una discusión abierta ya que el Código Penal no ofrece ningún tipo de información al respecto. Sólo se puede reconocer que no se puede ofrecer una solución general al problema de los límites entre del delito doloso y del delito imprudente, sino que estamos ante un problema de prueba o determinación fáctica con respecto a la presencia o ausencia de un conocimiento actual. ${ }^{71}$ Entendemos que desde la teoría jurídica del delito poco se puede aportar para solucionar esta cuestión, más que manifestar que el sujeto aceptó el posible resultado o puesta en peligro del bien jurídico protegido. Debe ser desde una teoría sobre la interpretación de los hechos la que determine la presencia del dolo eventual, es decir, la inseguridad jurídica se produce por falta de una teoría sobre cómo deben interpretarse unos hechos objetivos como prueba indiciaria de una categoría jurídica, en este caso, penal. $^{72}$

Así, podemos destacar algunas reglas que deben fundamentar un sistema de prueba de indicios: a) La mayor o menor potencialidad de la peligrosidad de la conducta; b) El conocimiento de estar infringiendo la normativa administrativa; c) La previsibilidad objetiva; en especial y en ámbito empresarial, la capacidad profesional del sujeto. Una mayor capacidad profesional supone un indicio de dolo eventual.

\section{Problemas concursales.}

El art. 291 CP plantea problemas concursales con otras figuras penales, en especial, respecto al art. 136 de la Ley General de Pesca y Acuicultura que remitimos a su estudio en un apartado posterior. En cuanto al delito de daños, los arts. 485 a $489 \mathrm{CP}$ protegen la propiedad privada, por lo que en el caso de que un vertido que ponga en peligro la salud vegetal, animal y pública, además, vulnere la propiedad privada deberemos acudir a concurso de delitos, normalmente, ideal (art. $75 \mathrm{CP}$ ). Entendemos que no resulta aplicable un concurso aparente de leyes (principio de consunción) ya que una parte importante de las

\footnotetext{
${ }^{70}$ FEIJOO SÁNCHEZ, Bernardo, "La distinción entre dolo e imprudencia en los delitos de resultado lesivo: Sobre la normativización del dolo", Cuadernos de Política Criminal, № 65 (1998), p. 324.

${ }^{71}$ Así, la determinación del dolo eventual se encuadra dentro de la problemática sobre la interpretación judicial de los hechos, sobre la coherencia narrativa de los hechos véase, MACCORMICK, N., Coherence in legal justification, Boston: Theory Legal Science, 1984.

${ }^{72}$ FERNÁNDEZ CRUZ, José Ángel, "El delito imprudente: la determinación de la diligencia debida en el seno de las organizaciones", Revista de Derecho- Facultad Ciencias Jurídicas de la UACH (2002), p. 115.
} 
MUÑOZ L., José; FERNÁNDEZ C., José Angel "Estudio dogmático penal de los artículos 291 del Código penal y 136 de la Ley General de Pesca y Acuicultura. A propósito del caso del Santuario de la Naturaleza Carlos Anwandter.

actividades contaminantes no conlleva normalmente un daño en la propiedad privada desde una perspectiva jurídico-civil.

\title{
6. El delito de daños a los recursos hidrológicos del art. 136 de la Ley General de Pesca y Acuicultura.
}

El art. 136 de la Ley General de Pesca y Acuicultura establece que:

\begin{abstract}
"El que introdujere o mandare introducir en el mar, rios, lagos o cualquier otro cuerpo de agua, agentes contaminantes químicos, biológicos o físicos que causen daño a los recursos hidrobiológicos, sin que previamente hayan sido neutralizados para evitar tales daños, serán sancionado con multa de 50 a 3.000 unidades tributarias mensuales. Si procediere con dolo, además de multa, la pena aplicar será la de presidio menor en su grado mínimo.
\end{abstract}

Si el responsable ejecuta medidas destinadas a reparar el daño causado y con ello se recupera el medio ambiente, el tribunal rebajará la multa en un cincuenta por ciento, sin perjuicios de las indemnizaciones que correspondan".

El art. 136 de la Ley General de Pesca (en adelante "LGP") recoge tanto un tipo doloso como uno imprudente. Muchos de los elementos del precepto coinciden con los descritos en el art. $291 \mathrm{CP}$ por lo que nos remitimos a su comentario, y nos centraremos en sus peculiaridades típicas.

Este precepto constituye, en cierta medida, un ejemplo de una mala técnica legislativa. El art. $136 \mathrm{LP}$ se aparta de una correcta técnica legislativa penal acorde con el principio de lesividad y subsidiariedad, ya que primero tipifica y describe el tipo imprudente, y posteriormente, en el inciso $2^{\circ}$ realiza una referencia al tipo doloso.

\subsection{Tipo doloso.}

El bien jurídico radica en la protección de los recursos hidrológicos y de su medio ambiente. En cuanto al primero de ellos, conforme con la LGP, estamos ante un tipo especial de daños. En cuanto a la referencia al medio ambiente como bien jurídico protegido viene reflejada de manera subsidiaria en la atenuante especial de reparación del daño que regula expresamente el precepto.

La conducta tipificada consta de dos elementos: el primero la introducción de agentes contaminantes en las aguas; y, en segundo lugar, la causación de un daño en los recursos hidrobiológicos; por tanto, se diferencia del art. 291 del CP en que se estructura como un genuino delito de resultado-lesión y no de resultado-peligro como vimos que estaba estructurado el art. 291 CP. No obstante, llama poderosamente la atención la comparación entre las penas de ambos preceptos. En efecto, resulta ciertamente extraño que aunque el art. 136 LGP se estructure como un delito de lesión, tenga menos pena que el art. $291 \mathrm{CP}$ que, como vimos, es de peligro. No tiene ningún sentido que un delito de lesión que pretende proteger similares bienes jurídicos tenga menos pena que un delito de peligro. $\mathrm{O}$, 
dicho en otros términos, que al sujeto podría salirle penalmente más beneficioso a efectos de pena lesionar los recursos hidrobiológicos en lugar de sólo ponerlos en peligro.

En primer lugar, debe determinarse qué se entiende como recursos hidrobiológicos. De la lectura de la LGP y, en especial, el art. 2 LGP -que enumera una larga lista de conceptos o interpretaciones legales- en sus números 36, 17 y 10 respectivamente, define como recursos hidrobiológicos, las "especies hidrobiológicas susceptibles de ser aprovechadas por el hombre". A la vez, especie hidrobiológica se define como "organismo en cualquier fase de su desarrollo, que tenga en el agua su medio normal o más frecuente de vida". Y dentro de las especies la LGP incluye las "especies objetivo", definidas como "aquellas especies hidrobiológicas sobre las cuales se orienta en forma habitual y principal el esfuerzo pesquero de una flota en una pesquería o en una unidad de pesquería determinada". Por lo tanto, podemos establecer que el resultado de esta figura delictiva se centra fundamentalmente en los recursos pesqueros $\mathrm{y}$, por tanto, nos encontramos ante un delito especial de daños.

Sorprendentemente, el precepto no está estructurado como una ley penal blanco, es decir, no requiere previamente una vulneración de una norma extrapenal. No obstante, la alusión a "sin que previamente hayan sido neutralizados para evitar tales daños" debe ser considerado como causa de atipicidad, que en muchos casos coincidirá con el cumplimiento de la normativa extrapenal, pero que en otros, incluso no cumpliendo con estas normas, la conducta será atípica si se demuestra que de facto -normalmente conforme con la Lex artis - se realizaron las actividades necesarias para evitar tales daños, por ejemplo, si se depuraron los vertidos antes de realizarlos.

El problema se plantea en los casos en que, a pesar de cumplirse con la normativa extrapenal, se producen daños en los recursos hidrológicos. Estos supuestos pueden resolverse, bien a través de las causales de justificación de cumplimiento de un deber o derecho, bien en un momento anterior: el de la imputación objetiva al haber creado un riesgo permitido.

Ahora bien, no todos los vertidos que han vulnerado una norma extrapenal entran dentro del art. 136 LGP. Efectivamente, si el vertido per se no conlleva un daño a los recursos hidrológicos la conducta será atípica, ya que no necesita una previa neutralización de sus efectos.

El art. 136 LGP en el ámbito de la participación parece tener presente la especial relación de la conducta prohibida con las estructuras empresariales. Así, al incluir el término "mandare introducir", nos señala la especial importancia de los tipos de inducción y, en especial, de autoría mediata en las modalidades comisivas de este delito.

\subsection{Tipo imprudente.}

El inciso $1^{\mathrm{o}}$ tipifica la comisión imprudente, donde no se requiere una especial gravedad, por lo que resulta suficiente la imprudencia simple. Ahora bien, los casos de imprudencia temeraria o grave deberán tener su reflejo en la concreta determinación de la pena. 
MUÑOZ L., José; FERNÁNDEZ C., José Angel "Estudio dogmático penal de los artículos 291 del Código penal y 136 de la Ley General de Pesca y Acuicultura. A propósito del caso del Santuario de la Naturaleza Carlos Anwandter.

Como hemos recalcado con anterioridad, una parte importante de los ataques al medio ambiente, $\mathrm{y}$, sin duda los más graves, se realizan en el seno de organizaciones con una estructura y distribución de funciones. De hecho, el establecimiento de unos criterios generales de imputación para determinar y comprobar respecto de cada uno de los intervinientes en el seno de los grupos organizados la falta de cuidado exigido, supone en la actualidad uno de los principales retos de la Teoría Jurídica del Delito.

6.3.1. La determinación de la omisión de la diligencia debida en el seno de las organizaciones de personas: los principios de confianza y de división del trabajo. ${ }^{73}$

El principio de confianza parte de la idea de que no constituye una obligación del ciudadano controlar de manera permanente a todos los demás, ya que en el caso contrario, la idea de responsabilidad quedaría destruida si todos los ciudadanos fuesen concebidos de modo exclusivamente cognitivo sino también como sujetos responsables. ${ }^{74}$ Este principio desarrollado por la jurisprudencia del Tribunal Supremo alemán, en relación con el tráfico motorizado, y que ha hallado también acogida en el Tribunal Supremo español- se presenta con especial intensidad en sectores compuestos por organizaciones de personas.

El escollo que plantea la aplicación práctica de este principio, radica en determinar el límite tolerado de confianza en el comportamiento cuidadoso de otros. Así, como presupuestos para su aplicación; en primer lugar, debe conocerse la cualificación de cada uno de los miembros de la organización; y en segundo lugar, distribuir el trabajo adecuadamente a las capacidades de cada uno de ellos. En el caso de que la delegación de funciones se haya verificado en una persona sin la cualificación necesaria, el correspondiente dominio del riesgo no se habrá transmitido. Además, este principio encontrará limitaciones cuando las circunstancias especiales (distracción, ebriedad, etc.) hacen probable, en el caso concreto, la lesión del deber de cuidado por parte del delegado en el control del riesgo. ${ }^{75}$

El principio de confianza en el ámbito profesional se suele denominar como el principio de división del trabajo. Sin duda, la división del trabajo, la atribución y delegación de funciones y la confianza -que necesariamente debe existir entre los diferentes estamentos jerárquicos y competenciales- constituyen la base organizativa de las modernas estructuras empresariales.

La teoría ha distinguido una división del trabajo de carácter horizontal, cuando se da igualdad de jerarquía competencial entre dos o más sujetos integrantes de una organización; y una división de carácter vertical, cuando los distintos sujetos se encuentran vinculados en una relación de subordinación jerárquica. Ello permite distinguir a su vez entre deberes de diligencia primarios y deberes de diligencia secundarios, estos últimos, referidos a los

\footnotetext{
${ }^{73}$ Véase, con mayor detenimiento, FERNÁNDEZ CRUZ, "El delito imprudente", cit. nota ${ }^{\circ} 72$, pp. 115121.

${ }^{74}$ CHOCLAN MONTALVO, José Antonio, Deber de cuidado y delito imprudente, Barcelona: Bosch, 1998, pp. 113-114.

${ }^{5}$ CHOCLAN MONTALVO, Deber de cuidado, cit. nota n ${ }^{\circ}$, p.115.
} 
deberes de control y vigilancia respecto del cumplimiento de la diligencia de sus colaboradores que conserva el delegante tras la delegación. ${ }^{76}$

En el supuesto de una delegación vertical y, en especial, cuando el control en origen está asignado a otras personas distintas de las que ejecutan directamente la conducta, el título de imputación penal de los encargados de adoptar las medidas de precaución será normalmente el de comisión por omisión, ${ }^{77}$ y esta posibilidad concurrirá en mayor medida, si el control que se impone preceptivamente constituye la principal función del órgano de vigilancia.

Cuando un grupo de personas participe a la vez en una determinada actividad peligrosa, deberá establecerse la capacitación de cada uno de ellos, y si nos encontramos en una organización vertical, deberá prestarse especial atención a las indicaciones y vigilancia respecto de sus subordinados. Uno de los elementos fundamentales para establecer la capacitación de cada uno de los miembros de la organización, resulta, sin duda, la posesión del adecuado título profesional. Sin bien a priori, no ofrece una especial complejidad determinar el título profesional de cada miembro de la organización, en la práctica suele plantearse la distinción entre el título general y la especialidad para ejercer la profesión.

De esta forma, lo esencial para la valida traslación del deber de garantía es que se lleve a cabo determinadas condiciones que permitan afirmar un dominio o control del riesgo por parte del delegado. En otras palabras, es necesario que el sujeto delegado tenga del dominio fáctico del riesgo derivado de la actividad.

No obstante, el delegado incompetente para la función delegada puede responder por la llamada culpa por asunción; cuando el sujeto incapaz para cumplir la función que se le ha encomendado con el cuidado necesario para salvaguardar la integridad de los bienes jurídicos protegidos, incumple el deber objetivo de cuidado consistente en abstenerse de aceptar el encargo para cuyo cumplimiento no está capacitado. La concurrencia de esta posibilidad resulta especialmente aplicable en los supuestos de división del trabajo horizontal, donde el delegado posee la formación, preparación y una posición jerárquica suficiente para rechazar la tarea o trabajo que le ha propuesto el delegante. ${ }^{78}$

En los supuestos de relación horizontal en ámbitos profesionales a la hora de imputar el resultado imprudente debe tenerse presente las siguientes consideraciones:

a) En primer lugar debe determinarse si el sujeto delegado está capacitado, tanto objetiva como subjetivamente para asumir la responsabilidad que se le encomienda. En caso afirmativo la responsabilidad se transmite a éste, quedando el delegante exonerado.

b) En segundo lugar, si no se ha transmitido la responsabilidad por falta de capacidad del sujeto delegado, se debe considerar, debido a la especial formación profesional de éste,

\footnotetext{
${ }^{76}$ CHOCLAN MONTALVO, Deber de cuidado, cit. nota n ${ }^{\circ}$ 74, p. 106.

${ }^{77}$ GIMBERNAT ORDEIG, Enrique, "Causalidad, omisión e imprudencia", $A D P C P, 1994$, pp. 45 y ss.

${ }^{78}$ GRACIA MARTÍN, Luis, El actuar en lugar de otro en Derecho penal, Universidad de Zaragoza, 1986, p. 222.
} 
MUÑOZ L., José; FERNÁNDEZ C., José Angel "Estudio dogmático penal de los artículos 291 del Código penal y 136 de la Ley General de Pesca y Acuicultura. A propósito del caso del Santuario de la Naturaleza Carlos Anwandter.

si se le pudo exigir que rechazara la acción propuesta. En caso afirmativo, concurrirá una culpa por asunción.

La delegación eficaz requiere además, que el delegado tenga a su disposición los medios necesarios, esto es, los recursos materiales y potestades de dirección para poder ejercer eficazmente la función de vigilancia y seguridad.

A modo de conclusión, a la hora de valorar la aplicación de este principio, resultará esencial que el directivo o coordinador haya observado el cuidado objetivamente debido al distribuir las tareas, coordinar la labor de equipo, seleccionar al personal auxiliar, y supervisar sus primeras actuaciones. Así, cuando menor sea la preparación real y la experiencia de sus colaboradores mayor será el deber de supervisión del directivo, y menor el campo de aplicación del principio de confianza. ${ }^{79}$

\section{Problemas concursales.}

A partir del estudio que hemos realizado de las figuras penales aplicables al caso de la contaminación del Santuario de la Naturaleza puede advertirse la eventual concurrencia de un concurso entre el tipo doloso del art. 136 LGP y el art. 291 CP. De una primera lectura superficial de ambos preceptos podríamos concluir que el art. 136 LGP se aplica preferentemente en virtud del principio de especialidad. En efecto, el citado precepto hace referencia a la introducción en un cuerpo de agua, en contraposición del art. 291 CP que no determina el ámbito espacial de la contaminación. Además, hemos manifestado con anterioridad que nos encontramos ante un delito de resultado, circunscrito a los recursos pesqueros. Desde esta interpretación, entonces podemos colegir, en principio, que la introducción de agentes contaminantes que no causen daños en los recursos hidrobiológicos, pero que sean susceptibles de producirlos, debe calificarse como tipos tentados o frustrados. Entonces, teniendo presente que las formas imperfectas de ejecución tienen la misma estructura típica que los delitos de peligro y la especialidad del ámbito espacial (el agua), podríamos afirmar su aplicación preferente respecto del delito de peligro del art. 291 CP. Solución que, en nuestra opinión, no resulta aceptable en la medida en que el art. 136 LGP impone una pena menor que el 291 CP.

Ahora bien, esta relación concursal sólo opera respecto a estos recursos económicos, ya que el art. $291 \mathrm{CP}$ resulta más amplio, protegiendo no sólo las especies hidrobiológicas, sino cualquier especie animal y vegetal, y lo que es más importante, la salud pública. Incluso, puede darse el supuesto que un vertido que produzca un daño en una especie hidrobiológica $\mathrm{y}$, además, ponga en peligro la salud de otras especies y/o la salud pública. Además, respecto al concurso entre los tipos tentados del delito de daños en los recursos hidrobiológicos y el delito de propagación indebida de agentes contaminantes, como hemos manifestado con anterioridad, éste último está estructurado como un delito de peligro hipotético, es decir, su ámbito de protección se adelanta al de los tipos tentados que coincide con el de los delitos de peligro concreto.

\footnotetext{
${ }^{79}$ CEREZO MIR, José, Curso de Derecho penal español. Parte General, (T. II) Madrid: Tecnos, 1998, p.
} 162. 
Teniendo presente las anteriores consideraciones podemos establecer los siguientes supuestos relacionados con la contaminación del Santuario:

7.1. Que la contaminación sólo haya producido un daño en los recursos hidrobiológicos. En este caso se aplicaría exclusivamente el art. 136 LGP. Solución esta que se enfrenta con el problema de imponer menos pena, a pesar de causar un daño, que la del art. $291 \mathrm{CP}$ que no exige la causación del daño sino sólo la puesta en peligro.

7.2. Que la contaminación ponga en peligro abstracto (hipotético) sólo los recursos hidrobiológicos. En este caso se aplicará el art. 291 CP. En cambio, si el peligro es concreto, entonces, paradójicamente, deberemos acudir a los tipos tentados y frustrados del art. 136 LP. Solución que también supone imponer menos pena que si aplicásemos el art. $291 \mathrm{CP}$.

7.3. Que la contaminación ponga en peligro cualquier otra especie animal o vegetal distinta a las incluidas en los recursos hidrobiológicos o la salud de las personas. En este caso, se aplicaría sólo el art. $291 \mathrm{CP}$.

7.4. Que la contaminación ponga en peligro concreto los recursos hidrobiológicos a que se refiere la LGP y, además, ponga en peligro abstracto cualquier otra especie animal o vegetal o la salud de las personas (291 CP). Concurso ideal entre tentativa o frustración del art. 136 LGP y el art. $291 \mathrm{CP}$.

7.5. Que la contaminación ponga en peligro cualquier otra especie animal o vegetal distinta a las incluidas en los recursos hidrobiológicos o la salud de las personas y, además, dañen estos recursos. En este supuesto, deberá aplicarse un concurso de delitos, en principio ideal, entre las dos figuras delictivas para abarcar la totalidad de los bienes jurídicos protegidos. Analizando esas soluciones y aplicándolas en concreto al caso CELCO, consideramos que la más adecuada es la c). Esto es, entender que sólo es de aplicación el art. 291 del CP. Las razones para optar por esta solución se basan, fundamentalmente, en los hechos que se deducen del Informe científico de la UACH. En efecto, en dicho Informe no se especifica que los vertidos supusieran ningún atentado para la fauna piscícola de la zona, sino para la vegetación -el luchecillo- y para los cisnes que, en virtud de las especificaciones de la LGP no son recursos hidrobiológicos. En consecuencia, no se puede aplicar este último precepto, ni siquiera en concurso con el art. $291 \mathrm{CP}$. No obstante, si se llegase a demostrar que la fauna piscícola del río sí fue puesta en peligro o lesionada, entonces la solución más apropiada serían la d) y e) respectivamente, esto es, un concurso ideal entre el art. $291 \mathrm{CP}$ y una tentativa, frustración o consumación del art. 136 de la LGP.

\section{Atenuante especial de reparación del daño.}

Estamos ante una de las principales virtudes del art. $136 \mathrm{LP}$, ya que la responsabilidad no se circunscribe a la reparación e indemnización de los daños particulares, sino que la amplía a los genuinos daños ambientales como por ejemplo, la restauración de los ecosistemas. 
MUÑOZ L., José; FERNÁNDEZ C., José Angel "Estudio dogmático penal de los artículos 291 del Código penal y 136 de la Ley General de Pesca y Acuicultura. A propósito del caso del Santuario de la Naturaleza Carlos Anwandter.

La atenuante parece exigir dos conductas al responsable del delito. Por una parte, reparar el daño causado, que debe entenderse a los recursos hidrobiológicos, y, por lo tanto, se centrará en la indemnización de los daños y perjuicios de los sujetos y empresas relacionados con la explotación de estos recursos. Por otra parte, la "recuperación del medio ambiente" producida como consecuencia del daño a los citados recursos.

No obstante, esta última exigencia resulta más problemática. Si la recuperación de la biodiversidad afectada se entendiera como una exigencia de retornar a la situación previa a la conducta realizada, en un gran de número de casos, resultaría imposible llevarla a cabo como consecuencia de las complejas relaciones físicas, químicas, biológicas, etc., que se producen en los casos graves de contaminación. Incluso alguna de ellas, aparecen con bastante posterioridad a la conducta e, incluso, a la celebración de juicio penal. A lo anterior, debemos añadir que, a pesar de haberse cometido un delito, el mero hecho de la existencia de una empresa potencialmente contaminante, conlleva una aceptación social de su actividad. En conclusión, esta segunda conducta reclamada por esta atenuante debe interpretarse conforme al contexto socio-económico, es decir, a las posibilidades técnicas, humanas y financieras. Por lo tanto, por "recuperar el medio ambiente" debe interpretarse más como una obligación de medios que de resultados. 
Polit. crim. Vol. 5, № 10 (Diciembre 2010), Art. 4, pp. 410 - 454.

[http://www.politicacriminal.cl/Vol_05/n_10/Vol5N10A4.pdf]

\section{BIBLIOGRAFÍA}

BACIGALUPO, Silvina, Autoría y Participación en los delitos de infracción de deber. Una investigación aplicable al Derecho penal de los negocios, Madrid: Marcial Pons, 2007.

BETANCOR RODRÍGUEZ/MUÑOZ LORENTE, "El caso Aznalcóllar: comentario al Auto de archivo de las diligencias desde las perspectivas jurídico-administrativa y penal", Revista Interdisciplinar de Gestión Ambiental, № 27, marzo de 2001, pp. 1 y ss.

CANCIO MELIÁ, M., "La responsabilidad del funcionario por delitos contra el medio ambiente en el Código Penal español”, $A D P C P$, Vol. LII (1999), pp. 137.

CEREZO MIR, J., Curso de Derecho penal español. Parte General, (T. II), Madrid: Tecnos, 1998.

CHOCLÁN MONTALVO, J. A., Deber de cuidado y delito imprudente, Barcelona: Bosch, 1998

CHRISTIE, N., ¿La nueva forma del holocausto?, Buenos Aires: Editores del Puerto, Trad.: COSTA, Sara, 1993.

Consejo Económico Social (España), Dictamen sobre el Anteproyecto de ley de Responsabilidad Civil derivada de Actividades con Incidencia Ambiental, 1999, en: http://www.ces.es/dictamenes/1999/dic0699.pdf

DUCE, Mauricio/RIEGO, Cristian, Proceso penal, Santiago: Editorial Jurídica de Chile, 2007 ,

FEIJOO SÁNCHEZ, B., "La distinción entre dolo e imprudencia en los delitos de resultado lesivo: Sobre la normativización del dolo", Cuadernos de Política Criminal, N$^{\circ} 65$ (1998).

, Normativización del Derecho penal y realidad social, Bogotá: Ed. Universidad Externado de Colombia, 2007.

, "Imputación de hechos delictivos en estructuras empresariales complejas", en: Centro de Investigación Interdisciplinaria en Derecho Penal Económico, 2009, pp. 1 y ss.

FERNÁNDEZ CRUZ, José Ángel, "El Nuevo Código Penal: una lucha por el discurso de la criminalidad", Polit. crim. no 1 (2006), A5, pp. 1 y ss.

, "El delito imprudente: la determinación de la diligencia debida en el seno de las organizaciones", Revista de Derecho- Facultad Ciencias Jurídicas de la UACH (2002).

GIMBERNAT ORDEIG, E., La causalidad en la omisión impropia y la llamada "omisión por omisión”, Buenos Aires: Rubinzal-Culzoni, 2003.

, "Causalidad, omisión e imprudencia", ADPCP (1994), pp. 45 y ss.

GÓMEZ BENÍTEZ, José Manuel, Teoría jurídica del delito. Parte general, Madrid: Civitas, Madrid, 1992.

GRACIA MARTIN, L., El actuar en lugar de otro en Derecho penal, Universidad de Zaragoza, 1986.

, "Los delitos de comisión por omisión. (Una exposición crítica de la doctrina dominante)", en: Modernas tendencias de la Ciencia del Derecho penal y 
MUÑOZ L., José; FERNÁNDEZ C., José Angel "Estudio dogmático penal de los artículos 291 del Código penal y 136 de la Ley General de Pesca y Acuicultura. A propósito del caso del Santuario de la Naturaleza Carlos Anwandter.

en la Criminología, Madrid: Universidad Nacional de Educación a Distancia, 2000, pp. 411 y ss.

HERNÁNDEZ, H., "El problema de la "causalidad general" en el derecho penal chileno (con ocasión del art. 232 del Anteproyecto de Nuevo código Penal)", Polít. crim. $\mathrm{N}^{\circ}$ 1 (2006), A7, pp. 19 y ss.

KAUFMANN, Armin, Dogmática de los delitos de omisión, Madrid: Marcial Pons, 2006.

MARTÍNEZ-BUJÁN PÉREZ, C., Derecho penal económico. Parte general, Valencia: Tirant lo Blanch, 1998.

MATUS ACUÑA, Jean Pierre, (et alii), “Análisis dogmático del derecho penal chileno, a la luz del derecho comparado y las obligaciones contraídas por Chile en el ámbito del derecho internacional. Conclusiones y propuesta legislativa fundada para una nueva protección penal del medio ambiente en Chile”, Ius et Praxis Vol. 9, No 2 (2003), pp. 1 y ss.

MATUS ACUÑA, Jean Pierre, (ed.), Derecho Penal del Medio Ambiente: estudios y propuestas para un nuevo Derecho Penal Medioambiental chileno, Santiago: Editorial Jurídica de Chile, 2004.

MATUS ACUÑA, Jean Pierre, "Fundamentos de la Propuesta de la Comisión Foro Penal para la Protección Penal del Medio Ambiente", Estudios Públicos N ${ }^{\circ} 110$ (2008), pp. 1 y ss., especialmente, pp. 17 y ss., accesible a través de la página web www.cepchile.cl

MIR PUIG, Santiago, Derecho penal. Parte general, (6 ed.) Barcelona: Reppertor, 2002.

MUÑOZ LORENTE, J., "El delito ecológico: su carácter de delito permanente y la interpretación de la agravación de clandestinidad", Revista Mensual de Gestión Ambiental $\mathrm{N}^{\circ}$ 7, julio de 1999, pp. 67 y ss.

, "Nula concreción por parte de la acusación de la norma administrativa vulnerada e integrante del delito ecológico del artículo 325 del Código Penal. La exención de responsabilidad por delito ecológico de los empleados subalternos que materialmente realizan los vertidos objeto del delito", Revista Mensual de Gestión Ambiental $\mathrm{N}^{\circ} 22$, octubre de 2000, pp. 39 y ss.

, "Obligaciones constitucionales de incriminación y Derecho Penal simbólico", Revista de Derecho y Proceso Penal (Aranzadi), º 6 (2001), pp. 103 y ss.

, "La responsabilidad civil derivada de los delitos contra el medio ambiente y el alcance y contenido del artículo 339 del Código Penal: una regla de responsabilidad civil sui generis de los delitos medioambientales. Diferenciación entre los daños por contaminación y los daños estrictamente ecológicos", Revista Interdisciplinar de Gestión Ambiental No 25, enero de 2001, pp. 47 y ss.

, "Algunas consideraciones sobre los delitos contra el medio ambiente en la jurisprudencia del Tribunal Supremo", Revista del Poder Judicial $\mathrm{N}^{\circ}$ 67 (2002), pp. 167 y ss.

PALAZZO, F.C., "Per una razionalizzazione della legislaciones complementare", Cassazione Penale $\mathrm{N}^{\circ} 1$, enero 2003, pp. 319 y ss.

RODRÍGUEZ COLLADO, L./OSSANDÓN WIDOW, M.M., Delitos contra la Función Pública ( $2^{\circ} \mathrm{ed}$.), Santiago: Editorial Jurídica de Chile, 2008.

ROXIN, Claus, Autoría y Participación, Madrid: Marcial Pons, 1998. 
Polít. crim. Vol. 5, № 10 (Diciembre 2010), Art. 4, pp. 410 - 454.

[http://www.politicacriminal.cl/Vol_05/n_10/Vol5N10A4.pdf]

SILVA SÁNCHEZ, J., Delitos contra el medio ambiente, Valencia: Tirant lo Blanch, 1999. TORÍO LÓPEZ, A., "Los delitos de peligro hipotético (Contribución al estudio diferencial de los delitos de peligro abstracto)", $A D P C P \mathrm{~N}^{\circ} 3$ (1981), pp. 825 y ss. 